\title{
Generation and nonlinear evolution of shore-oblique/transverse sand bars
}

\author{
By R. GARNIER ${ }^{1}$, D. CALVETE ${ }^{1}$, \\ A. FALQUES ${ }^{1}$ AND M. CABALLERIA ${ }^{2}$ \\ ${ }^{1}$ Departament de Física Aplicada, Universitat Politècnica de Catalunya, Campus Nord - Modùl B4, \\ 08034 Barcelona, Spain \\ ${ }^{2}$ Universitat de Vic, Grup de Recerca de Medi Ambient, C/de la Laura, 13, 08500 Vic, Spain
}

(Received 10 May 2005 and in revised form 3 May 2006)

The coupling between topography, waves and currents in the surf zone may selforganize to produce the formation of shore-transverse or shore-oblique sand bars on an otherwise alongshore uniform beach. In the absence of shore-parallel bars, this has been shown by previous studies of linear stability analysis, but is now extended to the finite-amplitude regime. To this end, a nonlinear model coupling wave transformation and breaking, a shallow-water equations solver, sediment transport and bed updating is developed. The sediment flux consists of a stirring factor multiplied by the depthaveraged current plus a downslope correction. It is found that the cross-shore profile of the ratio of stirring factor to water depth together with the wave incidence angle primarily determine the shape and the type of bars, either transverse or oblique to the shore. In the latter case, they can open an acute angle against the current (upcurrent oriented) or with the current (down-current oriented). At the initial stages of development, both the intensity of the instability which is responsible for the formation of the bars and the damping due to downslope transport grow at a similar rate with bar amplitude, the former being somewhat stronger. As bars keep on growing, their finite-amplitude shape either enhances downslope transport or weakens the instability mechanism so that an equilibrium between both opposing tendencies occurs, leading to a final saturated amplitude. The overall shape of the saturated bars in plan view is similar to that of the small-amplitude ones. However, the final spacings may be up to a factor of 2 larger and final celerities can also be about a factor of 2 smaller or larger. In the case of alongshore migrating bars, the asymmetry of the longshore sections, the lee being steeper than the stoss, is well reproduced. Complex dynamics with merging and splitting of individual bars sometimes occur. Finally, in the case of shore-normal incidence the rip currents in the troughs between the bars are jet-like while the onshore return flow is wider and weaker as is observed in nature.

\section{Introduction}

The surf zone of many sandy beaches exhibits morphological patterns which are rhythmic along the coast. These patterns are commonly not forced either by offshore bathymetric features or by man-made structures, so their origin has been an intriguing problem for decades. One type of such patterns consists of a longshore series of sand bars which are oriented perpendicular or oblique to the coast. They are usually attached to the coastline by cuspate features or salients called megacusps. The longshore spacing between consecutive bars (or consecutive megacusps) is relatively regular, 
in the order of tens to hundreds of metres. Such a type of rhythmic morphological systems was first systematically described by Evans (1938) and has been reported from many sites, either in low-energy beaches (Niederoda \& Tanner 1970; Falqués 1989) or in moderate energy environments (Guilcher, Godard \& Visseaux 1952; Hunter, Clifton \& Phillips 1979; Pedreros, Howa \& Michel 1996; Konicki \& Holman 2000; Lafon et al. 2002). These bars can be subtidal or intertidal systems (Lafon et al. 2002; Castelle 2004). Transverse/oblique bars may coexist with a longshore bar and they can even be associated with the seaward facing horns of a crescentic bar. However, they can also occur in the absence of any longshore bar (see Ribas, Falqués \& Montoto 2003).

Waves incoming obliquely to the coast drive a longshore current that may be quite strong, which suggests that such bars could form as dunes or free bars in rivers do, i.e. as a morphodynamic instability of the coupling of flow and morphology through the sediment transport. This classical hypothesis was first formulated by Sonu (1968) and has been explored since then by means of linear stability analysis in different model contexts. Ribas et al. (2003) summarizes and discusses the earlier linear stability analysis of Barcilon \& Lau (1973), Hino (1974), Christensen, Deigaard \& Fredsoe (1994) and Falqués, Montoto \& Iranzo (1996). All this previous work shows that, indeed, transverse and oblique bars may stem from a selforganization process involving the topography, the waves, the currents and the mobile seabed. However, the emerging patterns are sensitive to the mean beach profile, either barred or unbarred, and to the sediment transport description (Klein, Schuttelaars $\&$ Stive 2004; Ribas 2004). Several instability modes can appear and, in particular, the growing bars may be upcurrent or downcurrent oriented. This means that they may open an acute angle against the current or with the current, respectively (Evans 1938; Short 1994). In general, all the models predict a downcurrent migration of the bars.

In general, the linear stability analysis gives the initial tendency to grow or decay of the various coupled flow-morphology patterns. Thus, it is useful to identify positive feedback mechanisms between flow and morphology giving rise to the observed bed patterns and to give an indication of the relevant time and space scales. However, the assumption of infinitesimal amplitude of the linear analysis precludes any fully reliable comparison with field observations, since it is never verified by the observed bars. When the finite amplitude of the features is accounted for in a nonlinear stability analysis, the conclusion is sometimes that some of the predictions (shape, spacing, etc.) of the linear stability prevail for the finite-amplitude regime, but sometimes do not (Calvete $\&$ de Swart 2003). Thus, while the linear stability gives a suggestion, any true verification that morphodynamic instability is responsible for the formation of bars requires nonlinear stability analysis. In particular, any information on the final amplitude of the bars requires nonlinear analysis.

Nonlinear stability analysis of marine morphodynamic systems to model emerging patterns can be done with approximated semi-analytical methods based on power expansions in a small parameter. This typically leads to Ginzburg-Landau type equations and, although these methods are valid for the finite amplitude of the features, the conditions must be only slightly above critical, so they are known as weakly nonlinear analysis. They have been applied, for instance, to sand ripples by Blondeaux (1990), sand banks and sand waves by Komarova \& Newell (2000) and Idier \& Astruc (2003). Removing the assumption of small amplitude commonly requires the use of numerical models known as fully nonlinear models. This has been carried out in recent years with various techniques. The more traditional 
method considers the basic physical principles (momentum, water mass, sediment conservation) as partial differential equations, then discretizes them either by finite differences or by spectral methods and finally solves them. This method has been applied to the formation of crescentic bars by Damgaard et al. (2002) and by Reniers, Roelvink \& Thornton (2004) in case of shore-normal wave incidence. In a similar context and with a similar method, Caballeria et al. (2002) examined the finite-amplitude dynamics of both crescentic and transverse bars. Following a similar approach but with spectral methods, Nemeth (2003) investigated the formation of tidal sand waves. A second method still considers those governing partial differential equations, but discretizes them by using expansions in the linear stability modes. This procedure has been applied by Schuttelaars (1997) and Schramkowski, Schuttelaars $\&$ de Swart (2004) to tidal embayment dynamics and by Calvete \& de Swart (2003) to the formation of shoreface-connected sand ridges. Finally, a third method uses abstract rules to describe the basic physics of the system instead of using the partial differential equations (e.g. cellular automata). This procedure has been pursued by Werner \& Fink (1993) and Coco, Huntley \& O'Hare (2000) for the formation of beach cusps and by Ashton, Murray \& Arnault (2001) to the formation of large-scale shoreline sand waves.

As has been summarized in the last paragraph, nonlinear stability analysis has been applied to many morphodynamic systems. However, while those nonlinear models describe the growth of morphological features up to finite amplitude, the saturation process at some final amplitude is particularly difficult to describe. An exception is the study of the formation of shoreface-connected sand ridges up to finite amplitude along with its final nonlinear dynamics by Calvete \& de Swart (2003) and Roos et al. (2004). It was suggested that the saturation takes place as a balance between the instability mechanism and the damping due to gravitational downslope sediment transport, but a fully comprehensive explanation was not given. The instability source in that context was the positive feedback between the growing bed features and the perturbations on the current, thereinafter called 'bedflow' interaction. However, the corresponding situation in the surf zone is much more complex because of the presence of the breaking waves leading to the so-called 'bedsurf' coupling, namely, the coupling between the growing bed features and the wave field. Thus, in the existing models (Damgaard et al. 2002; Caballeria et al. 2002; Fachin \& Sancho 2004; Reniers et al. 2004) the saturation of the growth of bars either has not been reached or has not been discussed. Therefore, the finite-amplitude dynamics of surf zone transverse/oblique bars in the case of shore-oblique wave incidence remains largely unexplored.

Thus, our main goal here is to present a nonlinear stability analysis of surf zone morphodynamics to investigate the mechanisms by which bar growth can saturate. At the same time, the finite-amplitude characteristics of the emerging bars are analysed. To this end, a finite-difference numerical model that is an extension of morfo50 (Caballeria et al. 2002) has been developed. Both shore-normal and oblique wave incidence is considered. Two different sediment transport descriptions are used since existing linear stability analysis suggests that the type of sediment transport can have a profound influence on the shape of the emerging bars (Ribas et al. 2003). This is particularly true in the case of an unbarred beach and has motivated the choice of an unbarred beach for our study (Klein et al. 2004). The formulation of the so called morfo55 model and the basic states are described in $\S 2$. The numerical solutions of transverse and oblique bars are investigated in $\S 3$. Section 4 is dedicated to the physical interpretation of the growth and of the saturation of these instabilities, first 


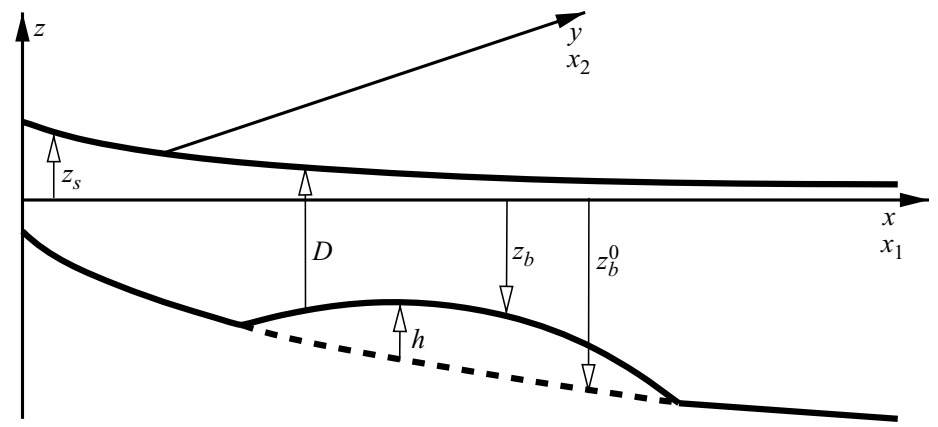

Figure 1. Coordinate system.

using a local analysis and then using a global analysis. Finally, the discussion and the conclusion are presented in $\S \S 5$ and 6 .

\section{Nonlinear numerical model}

The morfo55 nonlinear numerical model presented here is an extension of morfo50, a depth-averaged shallow-water equations solver with sediment transport and bed updating which was presented in Caballeria et al. (2002). Some improvements have now been introduced both for the hydrodynamics and for the morphodynamics.

\subsection{Governing equations}

The governing equations are based on the depth- and wave-averaged shallow-water equations described by Mei (1989). The origin $O$ of the Cartesian coordinate system $\left(O, x_{1}, x_{2}, z\right)$ is situated at an arbitrary point of the coastline which is assumed to be rectilinear (figure 1). The $x_{1}$-axis stands for the seaward cross-shore direction, the $x_{2}$-axis stands for the longshore direction and the $z$-axis stands for the upward vertical direction. The water mass conservation equation reads:

$$
\frac{\partial D}{\partial t}+\frac{\partial}{\partial x_{j}}\left(D v_{j}\right)=0
$$

where $D\left(x_{1}, x_{2}, t\right)$ is the total mean depth and $v\left(x_{1}, x_{2}, t\right)$ is the depth-averaged current vector $\left(\boldsymbol{v}=\left(v_{1}, v_{2}\right)\right)$.

The momentum conservation equations are:

$$
\frac{\partial v_{i}}{\partial t}+v_{j} \frac{\partial v_{i}}{\partial x_{j}}=-g \frac{\partial z_{s}}{\partial x_{i}}-\frac{1}{\rho D} \frac{\partial}{\partial x_{j}}\left(S_{i j}^{\prime}-S_{i j}^{\prime \prime}\right)-\frac{\tau_{b i}}{\rho D} \quad(i=1,2),
$$

where $z_{s}\left(x_{1}, x_{2}, t\right)$ is the mean sea level, $g$ is the acceleration due to gravity and $\rho$ the water density. The wave radiation stress tensor, $\boldsymbol{S}^{\prime}$, the turbulent Reynolds stress tensor, $\boldsymbol{S}^{\prime \prime}$, and the bed shear stress vector, $\boldsymbol{\tau}_{\boldsymbol{b}}$, are described below.

The main hydrodynamic improvement with respect to morfo50 has been the introduction of the wave energy density conservation equation including wave-current interaction and irregular waves, relaxing the assumption of a single breaking-point in Caballeria et al. (2002):

$$
\frac{\partial E}{\partial t}+\frac{\partial}{\partial x_{j}}\left(\left(v_{j}+c_{g j}\right) E\right)+S_{i j}^{\prime} \frac{\partial v_{j}}{\partial x_{i}}=-\varepsilon,
$$


where $E\left(x_{1}, x_{2}, t\right)$ is energy density defined by $E=\rho g H_{r m s}^{2} / 8 . H_{r m s}$ is the root mean square average of the wave height, $\boldsymbol{c}_{g}$ is the group velocity vector of the waves and $\varepsilon$ the dissipation rate due to wave breaking and bottom friction.

To couple the bottom level with hydrodynamic variables, the sediment mass conservation equation is used:

$$
\frac{\partial z_{b}}{\partial t}+\frac{1}{1-p} \frac{\partial q_{j}}{\partial x_{j}}=0
$$

where $z_{b}\left(x_{1}, x_{2}, t\right)$ is the mean bed level $\left(D=z_{s}-z_{b}\right), p$ is the sediment porosity $(p=0.4)$ and $\boldsymbol{q}$ is the horizontal sediment flux vector.

\subsection{Parameterization}

\subsubsection{Hydrodynamics}

As is common, only the processes we are interested in are described dynamically in the present study and the processes at smaller scale are parameterized. The former are the formation and evolution of the bars, the currents and the low-frequency waves. The latter consist of wind waves, turbulence, bed shear stress and sediment transport. The momentum input due to wind waves has been parameterized in the momentum equations (2.2) using the radiation stress tensor from the linear wave theory (Longuet-Higgins \& Stewart 1964):

$$
S_{i j}^{\prime}=E\left(\frac{c_{g}}{c} \frac{k_{i} k_{j}}{k^{2}}+\left(\frac{c_{g}}{c}-\frac{1}{2}\right) \delta_{i j}\right),
$$

with $\delta_{i j}$ being the Kronecker delta symbol and $c_{g}$ the modulus of the group velocity vector $c_{g}$. The phase velocity magnitude $c$ and the modulus $k$ of the wavenumber vector $\boldsymbol{k}$ satisfy the relationship: $\sigma=k c$, where $\sigma$ is the frequency of the incident wavetrain, i.e. $\sigma=2 \pi / T$ where $T$ is the wave period.

To compute $k, c, c_{g}$ and $c_{g}$, we use the four equations:

$$
\begin{aligned}
\sigma^{2} & =g k \tanh k D, & c & =\sqrt{\frac{g}{k} \tanh k D,} \\
c_{g} & =\frac{c}{2}\left(1+\frac{2 k D}{\sinh (2 k D)}\right), & c_{g i} & =\frac{k_{i}}{k} c_{g} .
\end{aligned}
$$

In the wave energy equation (2.3), both the dissipation rate by bottom friction and by breaking, $\varepsilon=\varepsilon_{f}+\varepsilon_{b}$, is accounted for. According to Horikawa (1988), the dissipation due to bottom friction, $\varepsilon_{f}$, is:

$$
\varepsilon_{f}=\frac{4}{3 \pi} \rho C_{d} \frac{\pi^{3} H_{r m s}^{3}}{T^{3}} \frac{1}{\sinh ^{3}(k D)} .
$$

For the dissipation due to wave breaking, the expression (Thornton \& Guza 1983)

$$
\varepsilon_{b}=\frac{3 \sqrt{\pi}}{16} B^{3} f_{p} \rho g \frac{H_{r m s}^{5}}{\gamma_{b}^{2} D^{3}}\left(1-\frac{1}{\left(1+\left(H_{r m s} / \gamma_{b} D\right)^{2}\right)^{5 / 2}}\right)
$$

is obtained by considering the Rayleigh distribution as the probability distribution for the wave height and taking into account that the largest waves are more likely to break. Here, $B$ is a breaking related coefficient $(B=1.0), f_{p}$ is the intrinsic frequency peak of the wave field, $f_{p}=\sigma / 2 \pi$, and $\gamma_{b}$ is the breaker index which has been fixed to $\gamma_{b}=0.42$ (Thornton \& Guza 1983). 
The wave angle is evaluated with the Snell law:

$$
k \sin \theta=k_{\infty} \sin \theta_{\infty},
$$

where $\theta$ is the wave angle defined as the angle between the wave rays and the $x_{1}$ axis, $k_{\infty}$ and $\theta_{\infty}$ are the wavenumber magnitude and the wave angle at the seaward boundary. This is exact for the alongshore uniform topography, but only a crude approximation when alongshore rhythmic features develop. Equation (2.5) has been used instead of the 'local Snell law' in Caballeria et al. (2002) because the local Snell law was very conducive to model breakdown due to the limit angle for wave refraction.

The momentum input from turbulence is described through the turbulent Reynolds stress

$$
S_{i j}^{\prime \prime}=\rho v_{t} D\left(\frac{\partial v_{i}}{\partial x_{j}}+\frac{\partial v_{j}}{\partial x_{i}}\right),
$$

where $v_{t}$ is the turbulent momentum horizontal diffusivity proposed by Battjes (1975), $v_{t}=M\left(\varepsilon_{b} / \rho\right)^{1 / 3} H_{r m s}$, where $M$ is the turbulence parameter (the value $M=1$ has been used here).

The bed shear stress in the momentum equations is an analytical approximation of the average over the Rayleigh distributed wave height and over the wave period of the instantaneous bed shear stress vector given by Mei (1989):

$$
\boldsymbol{\tau}_{b}^{i}=\rho C_{d}\left|\boldsymbol{v}+\boldsymbol{u}^{b}\right|\left(\boldsymbol{v}+\boldsymbol{u}^{b}\right),
$$

where $\boldsymbol{u}^{b}$ is the wave orbital velocity vector at the bottom.

\subsubsection{Sediment transport}

An important issue is the description of sediment flux in the bottom evolution equation (2.4). The results presented here correspond to the general total load sediment flux defined as:

$$
\boldsymbol{q}=\alpha\left(\boldsymbol{v}-\gamma u_{r m s}^{b} \nabla h\right),
$$

where $\alpha$ is the stirring factor, $\gamma$ the bedslope coefficient and $u_{r m s}^{b}$ the root-mean-square wave orbital velocity amplitude at the bottom defined as:

$$
u_{r m s}^{b}=\frac{\sigma H_{r m s}}{2 \sinh (k D)} .
$$

Here, the onshore transport driven by wave nonlinearity and undertow is assumed to be in balance with the gravitational downslope transport to build a certain equilibrium cross-shore beach profile, $z_{b}=z_{b}^{0}\left(x_{1}\right)$. When this equilibrium is broken by the growing bars, it is assumed that this will only cause a diffusive sediment transport proportional to the gradient of the bed level deviation from equilibrium, $h=z_{b}-z_{b}^{0}$. This simplification is motivated by the interest here in the growth of longshore non-uniformities rather than cross-shore migration of bars and has been commonly adopted in all the modelling studies on rhythmic topography (Deigaard et al. 1999; Caballeria et al. 2002; Damgaard et al. 2002; Ribas et al. 2003). It is physically based on the fact that the transport driven by the longshore current and rip currents is typically stronger than the transport directly driven by the waves (at least for well-developed rips).

Two different stirring factors are chosen, a cross-shore uniform or constant wave stirring $(\alpha=0.001 \mathrm{~m})$ and a function based on the Soulsby and Van Rijn formula (Soulsby 1997). The two choices will be hereinafter referred to as CWS and SVR, 
respectively. The main motivation for using the CWS transport is that it has been used in a number of existing stability studies (Hino 1974; Falqués, Coco \& Huntley 2000; Ribas et al. 2003). As argued in Falqués et al. (2000), a constant stirring may be associated with the situation where the infragravity wave energy is important. This can be seen from the Bailard formula (Bailard 1981) by considering (i) a wavedominated beach, i.e. a beach where the orbital velocity of waves is stronger than the current (Ribas et al. 2003) and (ii) a significant low-frequency wave energy (Falqués et al. 2000) whose shoreward increasing orbital velocity compensates the decrease induced by the breaking of high-frequency waves. The stirring factor corresponding to the SVR transport reads

$$
\begin{aligned}
\alpha & =A_{S}\left[\left(|\boldsymbol{v}|^{2}+\frac{0.018}{C_{D}} u_{r m s}^{b}\right)^{2}-u_{\text {crit }}\right]^{2.4} \text { if }\left(|\boldsymbol{v}|^{2}+\frac{0.018}{C_{D}} u_{r m s}^{b}\right)^{2}>u_{\text {crit }} \\
& =0 \quad \text { otherwise, }
\end{aligned}
$$

where the constant $A_{S}=A_{S S}+A_{S B}$ depends essentially on sediment characteristics and water depth and where $A_{S S}$ represents the suspended load transport and $A_{S B}$ the bedload transport (Soulsby 1997). The threshold current velocity for sediment transport $u_{\text {crit }}$ depends on sediment properties and depth (Soulsby 1997). The morphodynamic drag coefficient is defined by $C_{D}=\left(0.40 /\left(\ln \left(D / z_{0}\right)-1\right)^{2}\right.$. Contrarily to $C_{D}$, the drag coefficient used in the computation of the bed shear stress $\left(C_{d}\right)$ is constant to keep the same hydrodyamics independently of the transport formula. In the case of the SVR transport, some experiments were also made using a variable drag coefficient for the hydrodynamics and the results were not essentially different. The sediment grain size is given by $D_{50}=0.25 \mathrm{~mm}$ and $z_{0}=0.006 \mathrm{~m}$ is assumed.

The bedslope coefficient $\gamma$ is a critical parameter in our model which will differ depending on the stirring function used. There is a large uncertainty on its value and this is why a sensitivity study will be done. Nevertheless, a default value must be found for each stirring function by analogy with previous modelling studies. The difference between our SVR sediment transport formula and the original one (Soulsby 1997) is in the bedslope term where $|\boldsymbol{v}|$ has been substituted by $u_{r m s}^{b}$. The motivation is the following. Actually, both $|\boldsymbol{v}|$ and $u_{r m s}^{b}$ contribute to stirring the sediment and $u_{r m s}^{b}$ is typically larger than $|\boldsymbol{v}|$. Furthermore, for normal wave incidence the current vanishes in the basic state so that small topographic departures from equilibrium would not cause downslope transport which is unrealistic. Assuming the velocities are of order $1 \mathrm{~m} \mathrm{~s}^{-1}$, the original $\gamma$ advised by Soulsby (1997) was 1.6. Regarding Bailard's transport formula (Bailard 1981), the order of magnitude of $\gamma$ was 1.5 for the suspended load transport and 0.2 for the bedload transport. For the reference cases, $\gamma$ has been fixed to 1.5 with the SVR stirring and to 0.5 with the constant stirring.

\subsection{Numerical method}

The five equations: (2.1), (2.2) $)_{i=1,2},(2.3)$ and (2.4) with the five unknowns: $z_{s}\left(x_{1}, x_{2}, t\right)$, $v_{1}\left(x_{1}, x_{2}, t\right), v_{2}\left(x_{1}, x_{2}, t\right), H_{r m s}\left(x_{1}, x_{2}, t\right)$ and $z_{b}\left(x_{1}, x_{2}, t\right)$ have been solved numerically in order to describe the time evolution of a perturbed equilibrium beach under the wind wave forcing. For the sake of simplicity, the $x_{1}$ and $x_{2}$ axes will be referred to as $x$ and $y$ axes in the rest of the paper, and $v_{1}$ and $v_{2}$ will become $u$ and $v$.

\subsubsection{Equilibrium beach profile}

As in all stability models to explain the occurrence of complex morphological patterns, the patterns are supposed to form from an instability of a state where the 
patterns are absent. This state is here based on an alongshore uniform equilibrium beach profile which is taken from Yu \& Slinn (2003), but excluding the shore parallel bar:

$$
z_{b}^{0}(x)=-a_{0}-a_{1}\left(1-\frac{\beta_{2}}{\beta_{1}}\right) \tanh \left(\frac{\beta_{1} x}{a_{1}}\right)-\beta_{2} x .
$$

The motivation for not considering a longshore bar is twofold: (i) oblique/transverse bars are sometimes observed without the presence of those bars and (ii) even in case of a barred beach, the dynamics of bars observed at the inner surf zone close to the coastline are believed to be independent of the outer (alongshore uniform) shore-parallel bar. This is suggested by the linear stability analysis of Calvete et al. (2005) where, in this barred beach, transverse bars at the shore grow from a linear mode which fits with the initial state of our transverse bars evolution described later. Furthermore, previous modelling shows that oblique/transverse bars form in areas where there is significant wave breaking. Thus, this would occur next to the shore with the incident waves no matter whether there would have been a reduction of wave height on the bar or not. To avoid the complications of swash zone dynamics which are expected to have little influence on surf zone dynamics, the shoreline is assumed to consist of a vertical wall at $x=0$ with a small still-water depth, $a_{0}$, and to be fixed in time. Although this assumption filters out the dynamics of the formation of megacusps, the tendency for the formation of megacups in nature could still be inferred from model results if there is sediment accumulation/erosion at the (fixed) coastline. The value of $a_{0}$ has been chosen between $0.10 \mathrm{~m}$ to $0.25 \mathrm{~m}$, depending on the amplitude of the bathymetric patterns that will develop close to the shoreline. The other parameter is fixed to $a_{1}=2.97 \mathrm{~m}$ and the shoreline and offshore slopes are $\beta_{1}=0.075$ and $\beta_{2}=0.0064$. These parameters come from an approximation of the beach profile measured at Duck, North Carolina (Yu \& Slinn 2003).

Figure 2 shows some characteristic values of the system at the basic state. This is the equilibrium state reached by the system if there are no longshore irregularities, the morphodynamics remaining steady. In the next sections, when morphodynamic instabilities develop, the new equilibrium state eventually reached by the system is called the saturated state. The model is run on the concave up beach (cf. (2.7)) without any initial perturbation. At the offshore boundary, waves are assumed to approach from an angle with the shore-normal, $\theta=25^{\circ}$. The wave height is forced to increase from $H_{r m s}=0$ to $1 \mathrm{~m}$ within a time period of $5 \mathrm{~min}$. This gradual switching on of the wave height avoids strong transient oscillations from the hydrodynamic equations. After about $50 \mathrm{~min}$ the system became steady, the maximum longshore current being $v_{\max }=0.8 \mathrm{~m} \mathrm{~s}^{-1}$ at $x=11 \mathrm{~m}$. It is worth noting that in other related studies (e.g. Fachin \& Sancho 2004) the instability of the equilibrium state develops just from the unavoidable random numerical inaccuracies without any initial perturbation. In contrast, this is not the case with the present morfo55 model (also with morfo50, Caballeria et al. 2002). Without superposing initial disturbances to the equilibrium, the system state remains constant during all the simulation with the present model. Most probably, this is due to a higher numerical stability of the integration method. A representative value of the characteristic width of the surf zone is the distance from shore to the point of maximum breaking dissipation $\left(\varepsilon_{b}\right)$ which for this simulation turns out to be $x_{b}=11 \mathrm{~m}$. This 'maximum breaking' point is represented by the vertical dashed line.

According to previous studies where the sediment flux is described as a stirring factor multiplied by the current, the morphodynamic behaviour is mainly governed 
(a)

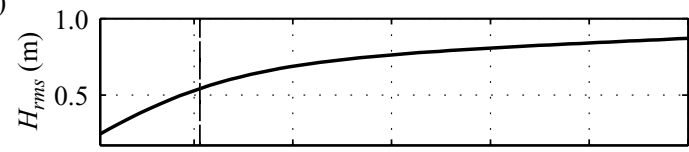

(b)

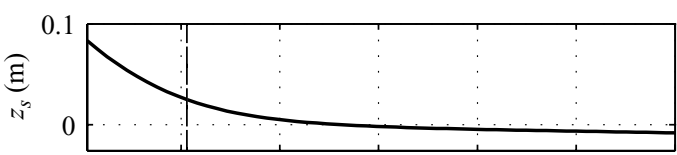

(c)

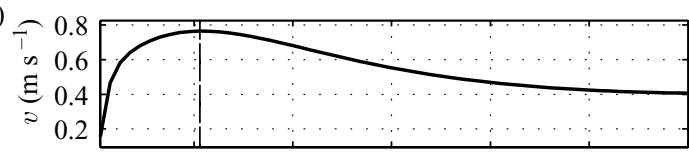

(d)

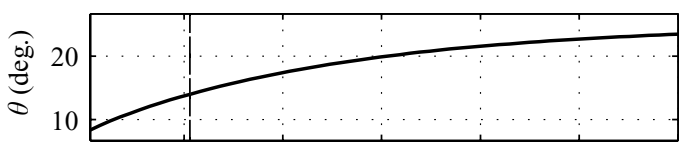

(e)

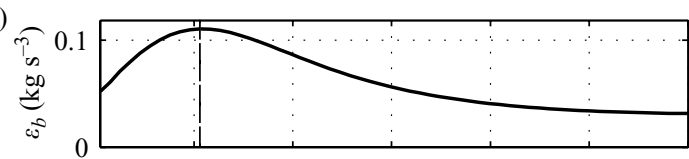

(f)

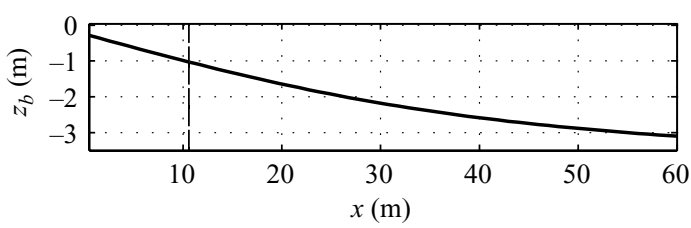

FIGURE 2. $H_{r m s}=1.0 \mathrm{~m}, T=6 \mathrm{~s}, \theta=25^{\circ}$. Equilibrium profiles of the basic state in the case of oblique wave incidence. $(a)$ Wave height $\left(H_{r m s}\right),(b)$ mean sea level $\left(z_{s}\right),(c)$ longshore velocity $(v)$, $(d)$ wave angle $(\theta),(e)$ dissipation rate $\left(\varepsilon_{b}\right)$ and $(f)$ bottom level $\left(z_{b}\right)$. Shoreline at $x=0$.

by the 'potential stirring', i.e. the stirring factor divided by water depth (Falqués et al. 2000; Coco et al. 2002; Ribas et al. 2003). Figure 3 shows that (i) for the SVR transport, in each case, the stirring factor and the potential stirring increase seaward at the inner surf zone and decrease seaward beyond a certain point and (ii) for the CWS transport, the stirring factor has been chosen approximately as the maximum of the SVR stirring and gives a seaward decreasing potential stirring.

\subsubsection{Boundary conditions}

The rectangular computational domain is defined as $0 \leqslant x \leqslant L_{x}$ cross-shore and $0 \leqslant y \leqslant L_{y}$ longshore. For each experiment, a large domain in the $y$-direction must be used to ascertain results are independent of $L_{y}$. In order to investigate rhythmic features along the coast, periodic boundary conditions for each variable and for its first $y$-derivative are assumed on the lateral boundaries (e.g. $z_{b}(, 0, t)=z_{b}\left(x, L_{y}, t\right)$ and $\left.\partial z_{b} / \partial y(x, 0, t)=\partial z_{b} / \partial y\left(x, L_{y}, t\right)\right)$.

At the off-shore boundary $\left(x=L_{x}\right), H_{r m s}$ is imposed. The sea and bed levels, $z_{s}, z_{b}$, are assumed free according to the mass conservation equation (2.1) and the bottom evolution equation (2.4), respectively. A radiation boundary condition is applied to the flow components $u$ and $v$ (Caballeria 2000) to ensure a seaward exponential 

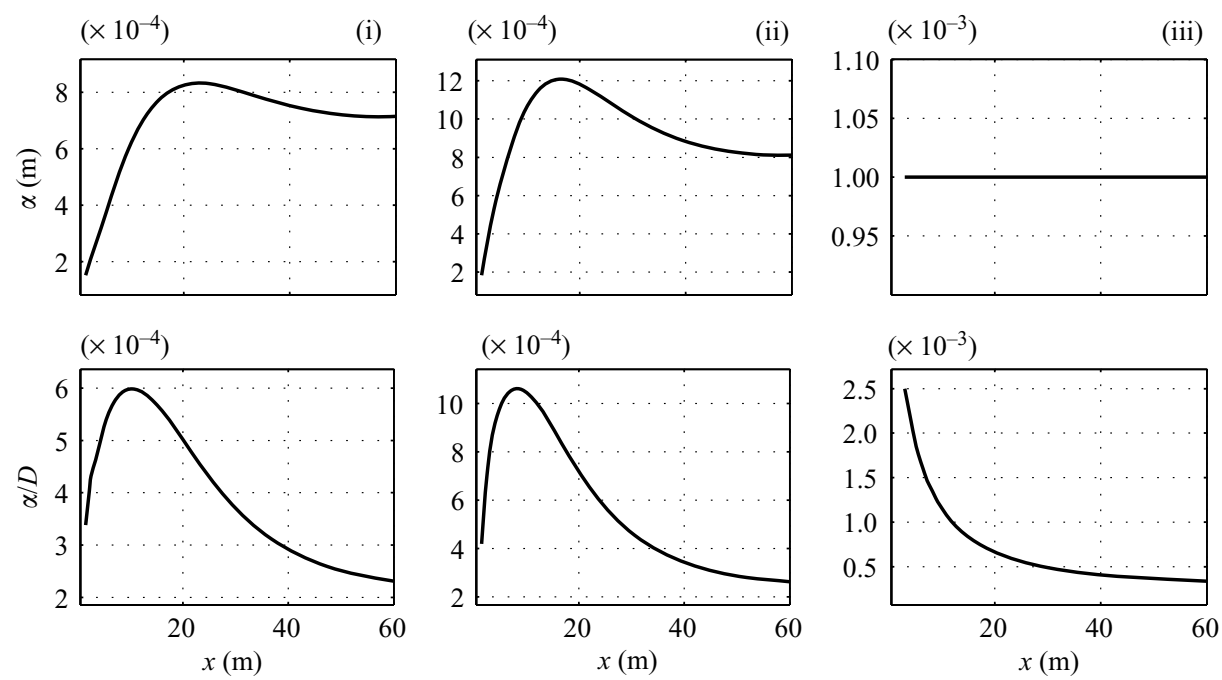

Figure 3. $H_{r m s}=1.0 \mathrm{~m}, T=6 \mathrm{~s}$. Stirring factor $\alpha$ (up) and potential stirring $\alpha / D$ (down) at the equilibrium state for three cases: (i) SVR transport, $\theta=0^{\circ}$, (ii) SVR transport, $\theta=25^{\circ}$, (iii) CWS transport, $\theta=25^{\circ}$.

decay. The motivation for this decay is that the flow pattern which is linked to the emerging surf zone bars is expected to be confined in the nearshore.

At the shore boundary $(x=0)$, a vanishing cross-shore flux and longshore current are imposed to be consistent with the artificial wall imposed at the shoreline and with the assumption of a viscous flow. The variables $z_{s}, z_{b}$ and $H_{r m s}$ are assumed to be free according to their respective conservation equations (2.1), (2.4) and (2.3).

\subsubsection{Discretization}

The finite-difference numerical scheme is essentially similar to that described in Caballeria (2000). The centred finite-difference method on a regular rectangular staggered grid is used for the spatial derivatives. The explicit Adams-Bashforth scheme for the temporal derivative required two Courant-Friedrichs-Levy (CFL) conditions owing to the parabolic and hyperbolic characters of the system of equations. The most restrictive is the numerical stability condition caused by the hyperbolic nature: $\Delta t \leqslant t_{C F L}$, with $t_{C F L}=c_{1} \min \{\Delta x, \Delta y\} / \sqrt{g D_{\max }}$ where $\Delta t$ is the time step and $(\Delta x, \Delta y)$ the grid spacing defined as $(\Delta x, \Delta y)=\left(L_{x} /\left(N_{x}-1\right), L_{y} / N_{y}\right)$ where $\left(N_{x}, N_{y}\right)$ is the number of points in the computational domain. The constant $c_{1}$ is determined empirically and is found to be about 0.1 (Caballeria 2000).

\section{Model results}

\subsection{Characteristic values}

\subsubsection{Input parameters}

The experiments have been done by using each sediment transport formula. The SVR transport in the case of normal wave incidence (SVR-i), oblique wave incidence (SVR-ii) and the CWS transport only in the case of oblique waves (CWS) will be presented, the case of normal wave incidence appearing to be stable in agreement with Falqués et al. (2000). All the experiments have been compared with a reference or default case which will be studied in detail here. 


\begin{tabular}{lccccccccc}
\hline Case & $L_{x}(\mathrm{~m})$ & $L_{y}(\mathrm{~m})$ & $\Delta x(\mathrm{~m})$ & $\Delta y(\mathrm{~m})$ & $a_{0}(\mathrm{~m})$ & $t_{C F L}(\mathrm{~s})$ & $\Delta t(\mathrm{~s})$ & $\Delta t_{M}(\mathrm{~s})$ & $t_{C P U}(\mathrm{~h})$ \\
SVR & 100 & 300 & 1.0 & 1.0 & 0.25 & 0.018 & 0.01 & 1.51 & 4.0 \\
CWS & 100 & 800 & 2.0 & 4.0 & 0.10 & 0.036 & 0.01 & 1.51 & 1.0
\end{tabular}

TABLE 1. Fixed input parameters for each sediment transport formula.

\begin{tabular}{|c|c|c|c|c|c|c|c|c|c|c|c|c|}
\hline \multirow[b]{2}{*}{ Case } & \multicolumn{3}{|c|}{$H_{r m s}(\mathrm{~m})$} & \multicolumn{3}{|c|}{$\theta$ (deg.) } & \multicolumn{3}{|c|}{$T(\mathrm{~s})$} & \multicolumn{3}{|c|}{$\gamma$} \\
\hline & $\overline{\text { Def }}$ & Min & $\overline{\operatorname{Max}}$ & $\overline{\text { Def }}$ & Min & $\overline{\operatorname{Max}}$ & $\overline{\text { Def }}$ & Min & $\overline{\operatorname{Max}}$ & $\overline{\text { Def }}$ & Min & $\overline{\operatorname{Max}}$ \\
\hline DD: & 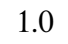 & 0.5 & 1. & 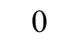 & - & . & 6 & 6 & 12 & 1.5 & 1 & 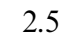 \\
\hline & 1.0 & 0.5 & 1.2 & 25 & 5 & 45 & 0 & 6 & 1 & 1. & 1.5 & 1.8 \\
\hline CWS & 1.0 & 0.5 & 1.25 & 25 & 5 & 45 & 6 & 6 & 12 & 0.5 & 0.3 & 0.9 \\
\hline
\end{tabular}

TABLE 2. Variable input parameters for each experiment. Default (def), minimum (min) and maximum $(\max )$ values.

The fixed input parameters arbitrarily set for each sediment transport formula are shown in table 1. $L_{x}$ is the same for all experiments in order to keep the same equilibrium cross-shore profile independently of the sediment transport used, whereas $L_{y}$ is chosen to be about 10 times the final spacing of bars for the reference cases. As the longshore length of the integration domain artificially imposes a final spacing of bars as a divisor of $L_{y}$, the relative error of this final spacing will be of about $10 \%$. $\Delta x$ depends on the cross-shore span of the bars, a bar must be described by more than 15 points in the off-shore direction and $\Delta y$ must be sufficiently small to avoid numerical oscillations. The height of the artificial wall at the coastline depends on the distance from the coastline to the top of the bars. The morphodynamic processes have been artificially accelerated by a factor 150 for computational convenience (see Caballeria 2000), giving the morphodynamic time step as: $\Delta t_{M}=150 \Delta t$. This acceleration factor has been empirically determined on small computational domains obtaining the same results by using it or not. Finally, $t_{C P U}$ is defined as the CPU time corresponding to 1 day of beach evolution using a Pentium IV, $2.8 \mathrm{GHz}$.

In order to excite the system and develop the instabilities, the longshore uniformity has been broken off by adding a smoothed random function to the initial bathymetry. In order to check that the final state does not depend on the particular choice of the initial conditions, a 'Dirac-function like' initial perturbation has been considered as well. Similarly, several domain lengths have also been tested. Although the particular intermediate states may differ from test to test, the final state and the growth rate of the instabilities were the same.

Each reference case is characterized by a wave forcing at the offshore boundary $\left(H_{r m s}, \theta, T\right)$ and by the bedslope parameter $(\gamma)$. The influence of these parameters will also be investigated. The default value of these variables and the minimum (maximum) value studied are shown in table 2.

\subsubsection{Characteristics of the bars}

As in nature, the bars generated by a nonlinear model starting with random initial conditions may have a relatively irregular shape whose quantitative characterization is not straightforward. To this end, six time-dependent quantities have been used. (i) The amplitude $A_{m}(\mathrm{~m})$ is defined as $A_{m}=0.5\left(h_{\max }-h_{\min }\right)$, where $h_{\max }\left(h_{\min }\right)$ is the maximum (minimum) value of $h$ throughout the model domain. (ii) The angle $\beta_{m}$ (deg.) $(\geqslant 0)$ is the mean of the angle formed by crests and troughs with the $x$-axis. 


$\begin{array}{lcccccccccc}\text { Case } & \text { Mode } & \begin{array}{c}A_{m} \\ (\mathrm{~m})\end{array} & \begin{array}{c}\beta_{m} \\ (\mathrm{deg})\end{array} & \begin{array}{c}\lambda_{\text {mean }} \\ (\mathrm{m})\end{array} & \begin{array}{c}\lambda_{m} \\ (\mathrm{~m})\end{array} & \begin{array}{c}S_{m} \\ (\mathrm{~m})\end{array} & \begin{array}{c}L_{m} \\ (\mathrm{~m})\end{array} & \begin{array}{c}T_{m} \\ (\mathrm{day})\end{array} & \begin{array}{c}\sigma_{m} \\ \left(\mathrm{day}^{-1}\right)\end{array} & \begin{array}{c}c_{m} \\ \left(\mathrm{~m} \mathrm{day}^{-1}\right)\end{array} \\ \text { SVR-i } & & 0.13 & 0 & 30 & 30 & 11 & 11 & - & 2.1 & 0 \\ \text { SVR-ii } & 1 & 0.37 & 51 & 30 & 30 & 19 & 30 & 0.18 & 1.6 & 167 \\ \text { CWS } & 1 & 0.28 & 34 & 50 & 50 & 30 & 36 & 0.7 & 1.25 & 71 \\ & 2 & 0.26 & 49 & 73 & 73 & 40 & 61 & 1.7 & 0.7 & 43\end{array}$

TABLE 3. Characteristics of the dominant modes for the default case.

It may be either 'up' or 'down' according to whether bars are up-current or downcurrent and it is zero for transverse bars. (iii) The longshore mean spacing $\lambda_{\text {mean }}(\mathrm{m})$ is the average spacing between two crests of bars which is obtained by counting the number of bar crests in a longshore section along the domain. (iv) The longshore dominant spacing $\lambda_{m}(\mathrm{~m})$ is the dominant wavelength of bars according to Fourier analysis. To this end, we use the discrete Fourier transform of the bed level at the longshore section $x=10 \mathrm{~m}$ :

$\mathscr{H}\left(k_{l}\right)=\sum_{j=1}^{N_{y}} h\left(10, y_{j}\right) \exp \left(-\mathrm{i} \frac{2 \pi}{N_{y}}(j-1)(l-1)\right), \quad k_{l}=\frac{2 \pi(l-1)}{L_{y}}, \quad l=1: N_{y}$,

where $\mathscr{H}\left(k_{l}\right)$ is the Fourier coefficient corresponding to the wavenumber of the topographic signal $k_{l}$ and $y_{j}=j \Delta y$. The normalized modulus of the Fourier coefficients is defined as $|\mathscr{H}|_{n}\left(k_{l}\right)=\left|\mathscr{H}\left(k_{l}\right)\right| / \max _{k_{l}}\left|\mathscr{H}\left(k_{l}\right)\right|$. The wavenumber for which $\left|\mathscr{H}\left(k_{l}\right)\right|$ is maximum defines the dominant mode and is called $k_{m}$. Finally, the variables with the subscript $m$ correspond to the dominant mode and the variables with the subscript $l$ correspond to any mode with the wavenumber $k_{l}$, for example $\lambda_{m}=\lambda_{l=m}=2 \pi / k_{m}$. (v) The cross-shore span $S_{m}(\mathrm{~m})$ is the mean horizontal crossshore approximate span of bar crests and bar troughs. (vi) The total approximate span or length $L_{m}(\mathrm{~m})$ is given by $S_{m} / \cos \left(\beta_{m}\right)$. Furthermore, the temporal behaviour of bars will be characterized by three quantities. (i) The period $T_{m}$ (day) is the time that the bars spend in travelling across one dominant spacing. (ii) The growth rate $\sigma_{m}\left(\right.$ day $\left.^{-1}\right)$ is obtained plotting the time evolution of $\left|\mathscr{H}\left(k_{l}\right)\right|$. At the initial stages of the simulation, the perturbations are expected to grow exponentially in time, consistent with the linear stability theory. This means that for each wavenumber $k_{l}, \mathscr{H}\left(k_{l}, t\right) \approx \mathscr{H}\left(k_{l}, 0\right) \exp \left(\sigma_{l} t\right)$. Thus, by taking the logarithm of the modulus, its real growth rate, $\operatorname{Re}\left(\sigma_{l}\right)$, can be isolated from: $\ln \left|\mathscr{H}\left(k_{l}, t\right)\right| \approx \operatorname{Re}\left(\sigma_{l}\right) t+\ln \left|\mathscr{H}\left(k_{l}, 0\right)\right|$. Therefore, the initial growth of $\ln \left|\mathscr{H}\left(k_{l}, t\right)\right|$ for each wavenumber $k_{l}$ should be a straight line with a slope $\operatorname{Re}\left(\sigma_{l}\right)$. For the dominant mode, we define $\sigma_{m}=\operatorname{Re}\left(\sigma_{l=m}\right)$. (iii) The migration velocity $c_{m}\left(\mathrm{~m}\right.$ day $\left.^{-1}\right)$ is calculated as $\lambda_{m} / T_{m}$.

\subsection{Default cases}

\subsubsection{SVR transport, normal incident waves ( $S V R-i)$}

Figure 4 shows four steps of the evolution of the topography during 8 days. The domain has been reduced for the visualization: $(0 \mathrm{~m}<x<30 \mathrm{~m}$ and $50 \mathrm{~m}$ $<y<150 \mathrm{~m}$ ). At day 1, the initial random perturbations seem erased and the total depth seems longitudinally uniform. At day 2 , regular and gentle transverse bars with an amplitude up to $5 \mathrm{~cm}$ appear with a spacing of $\lambda_{\text {mean }}=20 \mathrm{~m}$. They will grow and merge together until the system reaches its final state at day 8 . The final characteristics of these bars are given in table 3: the bar amplitude is $A_{m}=0.13 \mathrm{~m}$, the mean spacing 
Day 0

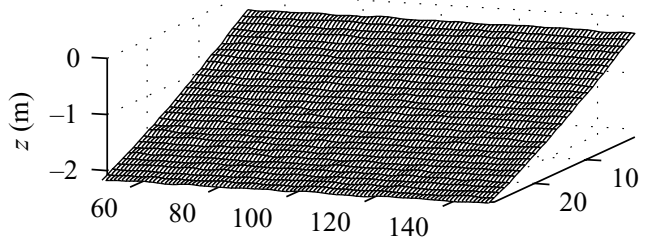

Day 2

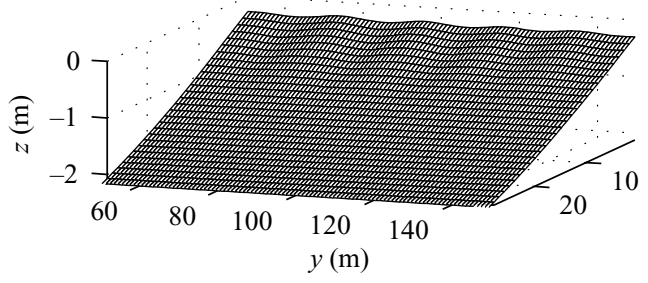

Day 1

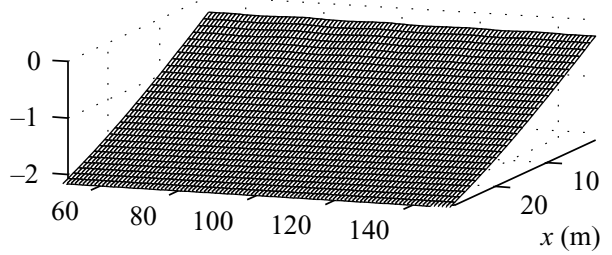

Day 8

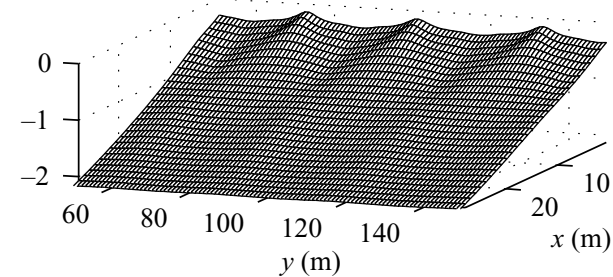

FIGURE 4. SVR transport, $H_{r m s}=1.0 \mathrm{~m}, T=6 \mathrm{~s}, \theta=0^{\circ}$. Zoom of the total bathymetry during the formation, development and growth saturation of shore-transverse bars.

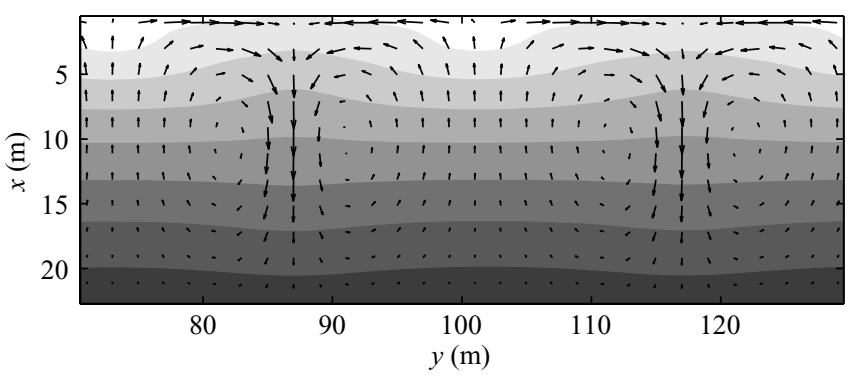

FIGURE 5. SVR transport, $H_{r m s}=1.0 \mathrm{~m}, T=6 \mathrm{~s}, \theta=0^{\circ}$. Final state (day 8). Bathymetric contours $\left(z_{b}\right)$ and circulation $(\boldsymbol{v})$ over transverse bars. Shallowest areas are white and deepest areas are shaded.

is $\lambda_{\text {mean }}=30 \mathrm{~m}$ and the cross-shore span is the size of the surf zone, $S_{m}=x_{b}=11 \mathrm{~m}$. Figure 5 is a top view of the final bathymetry and circulation. The latter consists of a very clear rip-current system, the current going offshore at the troughs and onshore over the shoals. It is also apparent that, as is observed in nature, the seaward flowing current is narrow, jet-like and stronger than the shoreward flow which is wider and weaker. The maximum seaward current is $|u|=0.38 \mathrm{~m} \mathrm{~s}^{-1}$ and the maximum feeder current (longshore current) is $|v|=0.37 \mathrm{~m} \mathrm{~s}^{-1}$. A more precise description of the dynamics of these bars may be obtained by looking at the time evolution curves. The crests and the troughs of the bars can be seen in figure 6(a). As described in figure 4, bars are very subtle until day 2 . Between days 2 and 4 , the merging of some of the bars can be seen. At day 6, the state of the bars seems very close to the final state at day 8. It is also clear that crests and troughs remain parallel to the time axis, showing the non-migration of the bars. Merging of bars (and also splitting) is shown in figure $6(b)$ where the different steps presented in figure $6(a)$ are recovered. It can be seen that the number of bars in the domain systematically decreases from day 1 until the final state where $\lambda_{\text {mean }}=30 \mathrm{~m}$. Figure $6(\mathrm{c})$ shows that at the beginning of the simulation, the spectral energy is randomly distributed among the different wavenumbers consistently 

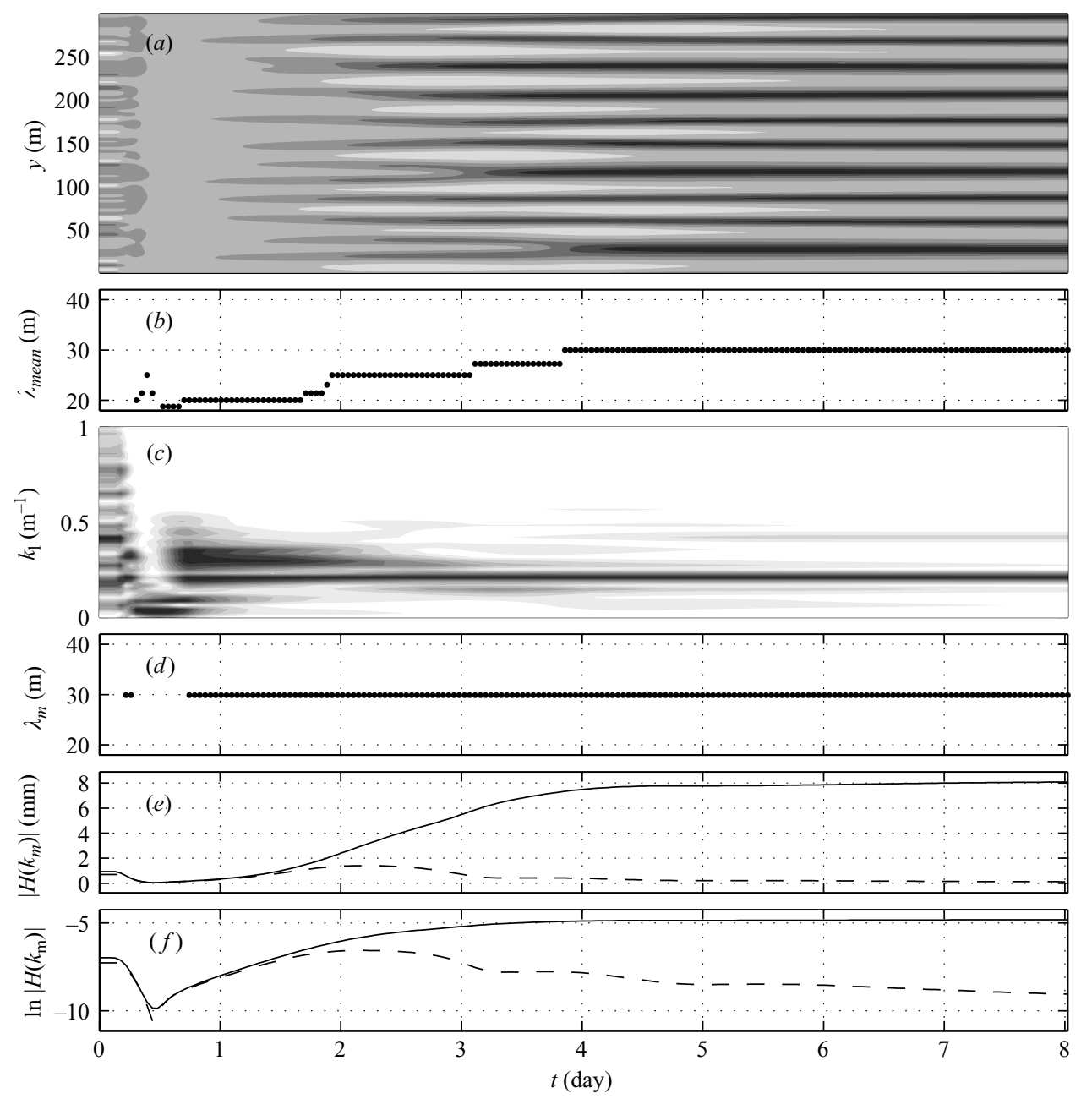

FIgURE 6. SVR transport, $H_{r m s}=1.0 \mathrm{~m}, T=6 \mathrm{~s}, \theta=0^{\circ}$. Time series of $(a)$ the bed level along the longshore section at $x=10 \mathrm{~m}(h(y, t))$, crests are white and troughs are black, $(b)$ the mean spacing of the bars $\left(\lambda_{\text {mean }}(t)\right),(c)$ the normalized modulus of the Fourier coefficient of the topographic signal $\left(|\mathscr{H}|_{n}\left(k_{l}, t\right)\right),(d)$ the resulting predominant spacing of bars $\left(\lambda_{m}(t)\right)$, (e) the two predominant most energetic (non-normalized) Fourier coefficients of the topographic signal $\left(|\mathscr{H}|\left(k_{l}, t\right)\right)$, corresponding to: $\lambda_{m}=2 \pi / k_{m}=20 \mathrm{~m}$ (dashed line), $\lambda_{m}=30 \mathrm{~m}$ (thick line), and $(f)$ their logarithmic value $\left(\ln \left|\mathscr{H}\left(k_{m}, t\right)\right|\right)$.

with the randomness of the initial perturbation, and after day 1 , one wavenumber becomes clearly dominant. It is important to notice the difference between the mean spacing (figure $6 b$ ) and the dominant spacing (figure $6 d$ ). Indeed, as seen in this plot, the time when $\lambda_{m}$ grows does not necessarily correspond to the merging of bars, i.e. the time when $\lambda_{\text {mean }}$ is increasing. At the final steady state, however, both wavelengths coincide, $\lambda_{m}=\lambda_{\text {mean }}=30 \mathrm{~m}$. This plot indicates that at day 1 the finally dominant wavelength is already dominant. The final spacing actually corresponds to an instability mode which appears very soon in the evolution, but other modes are also present during all the simulation. The nonlinear competition between all these modes accounts for $\lambda_{m} \neq \lambda_{\text {mean }}$, but the other modes never dominate upon the finally dominant mode. Figure $6(e)$ shows the time evolution of the two largest Fourier 
Day 0

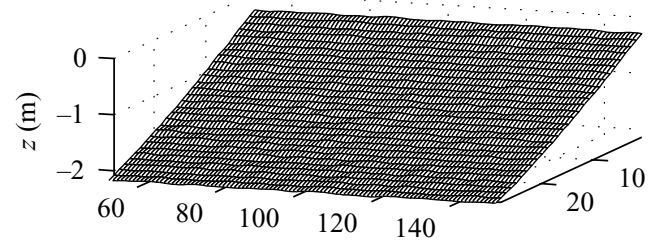

Day 3

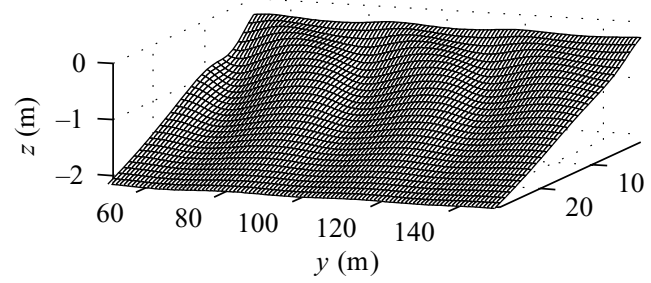

Day 1

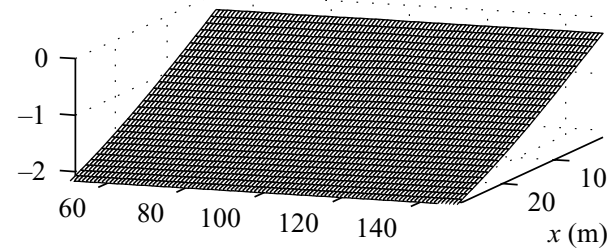

Day 8

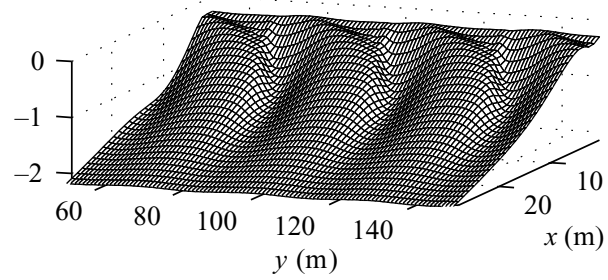

FigURE 7. SVR transport, $H_{r m s}=1.0 \mathrm{~m}, T=6 \mathrm{~s}, \theta=25^{\circ}$. Zoom of the total bathymetry during the formation, development and growth saturation of oblique down-current oriented bars.

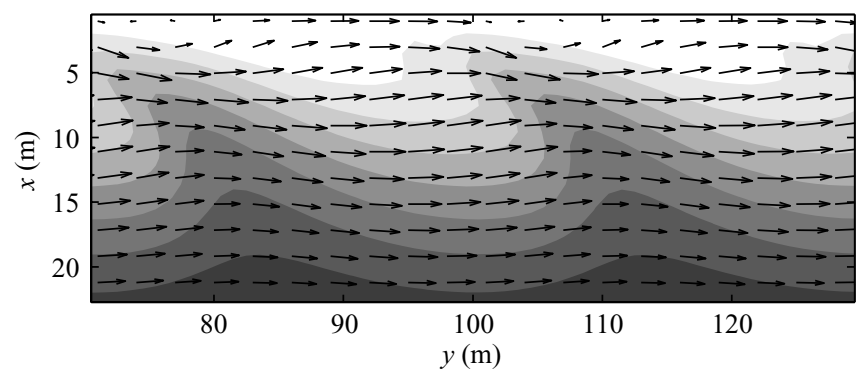

FiguRE 8. SVR transport, $H_{r m s}=1.0 \mathrm{~m}, T=6 \mathrm{~s}, \theta=25^{\circ}$. Final state (day 14). Bathymetric contours $\left(z_{b}\right)$ and circulation $(\boldsymbol{v})$ over down-current oriented bars. Shallowest areas are white and deepest areas are shaded.

coefficients $\left|\mathscr{H}\left(k_{l}, t\right)\right|$ : the dominant one during all the evolution and the second one at the initial stage. The slope of the linear part of each curve of figure $6(f)$ gives a very similar growth rate for the two modes: $\sigma_{m}=2.3$ day $^{-1}$.

\subsubsection{SVR transport, oblique waves (SVR-ii)}

As shown in figure 7 , bars trending obliquely to the coast with a down-current orientation appear in this case. They have reached the middle of the growth at day 3 and the final saturated states are obtained at day 8 when the amplitude of the bars is $A_{m}=0.37 \mathrm{~m}$ (table 3 ). At this state, they have adopted a backward curved shape in plan view with the seaward tip of the bar becoming perpendicular to the coast rather than oblique. A meandering of the longshore current is observed as a result of the bars (figure 8), the current being deflected onshore over the crests and offshore over the troughs. This meandering is consistent with previous studies (Ribas et al. 2003) and has been called 'current refraction'. The deflection is relatively weak, the cross-shore flow component being smaller than the longshore component (up to $|u| \simeq 0.3 \mathrm{~m} \mathrm{~s}^{-1}$ in comparison with $|v| \simeq 0.9 \mathrm{~m} \mathrm{~s}^{-1}$ ). The most significant deflection occurs close to the shoreline, especially at the troughs. The formation of bars is clearly visible in figure $9(a)$ between days 2 and 4 . The down-current migration of the bars is easily 


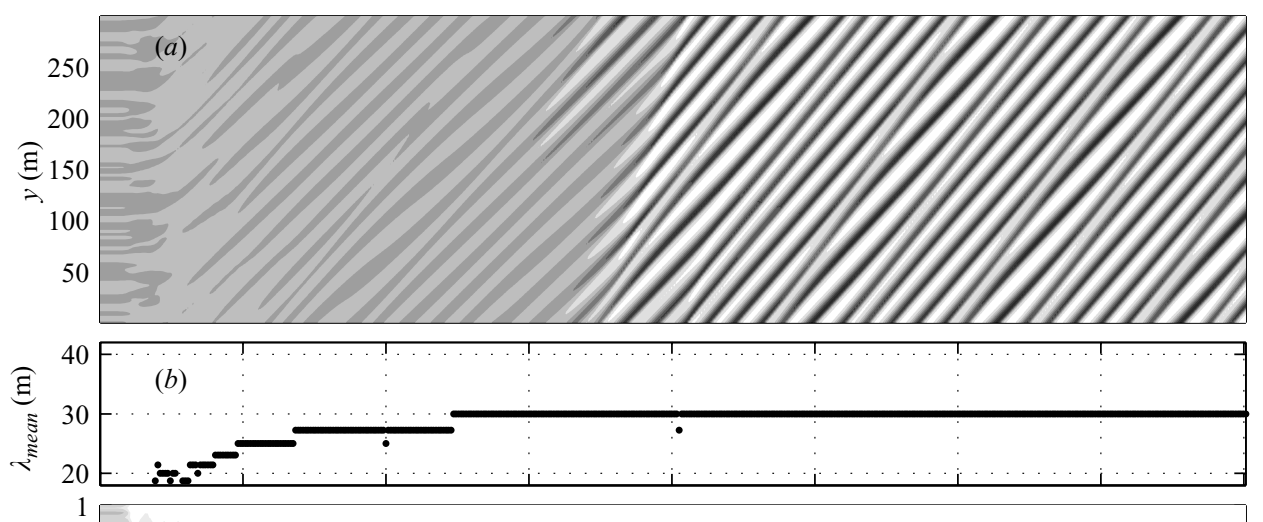

(c)
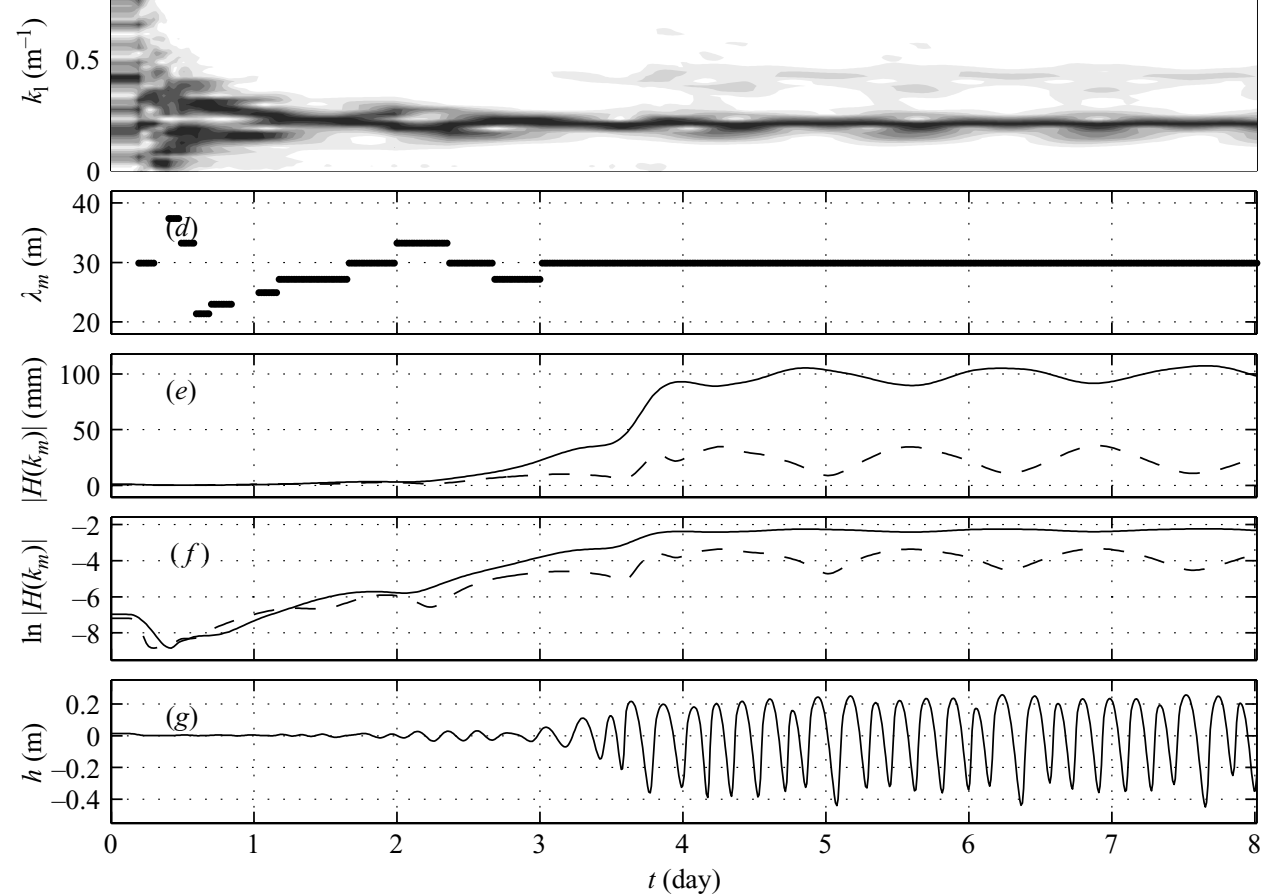

FIGURE 9. SVR transport, $H_{r m s}=1.0 \mathrm{~m}, T=6 \mathrm{~s}, \theta=25^{\circ}$. The graph description is the same as figure 6 with $(\mathrm{g})$ the time evolution of the bottom perturbation at one point: $(x=10 \mathrm{~m}$, $y=22.5 \mathrm{~m})$. For $(e)$ and $(f), \lambda_{m}=2 \pi / k_{m}=25 \mathrm{~m}$ (dashed line), $\lambda_{m}=30 \mathrm{~m}$ (thick line).

seen through the slope of the dark and white strips. In the final saturated state, bars move about $300 \mathrm{~m}$ within 1.8 days so that the migration celerity is about $c_{m}=167 \mathrm{~m}$ day $^{-1}$. The mean shows four steps of wavelength $\lambda_{\text {mean }}$ remains constant to $30 \mathrm{~m}$ from day 3 (figure $9 b$ ), indicating that there is no clear merging/splitting after the waves have reached their final amplitude, in contrast with the case of transverse bars. Figure $9(c)$ shows the initial uniformly distributed spectral energy and the process of energy concentration at wavelengths of $20 \mathrm{~m}$ and larger during the first three days. For example, a mode with $\lambda_{m}=25 \mathrm{~m}$ emerges from this process and becomes dominant at day 1 . At the same time, the finally dominant mode, $\lambda=30 \mathrm{~m}$, is already present and competes with that one. This competition can be clearly seen in the plot 

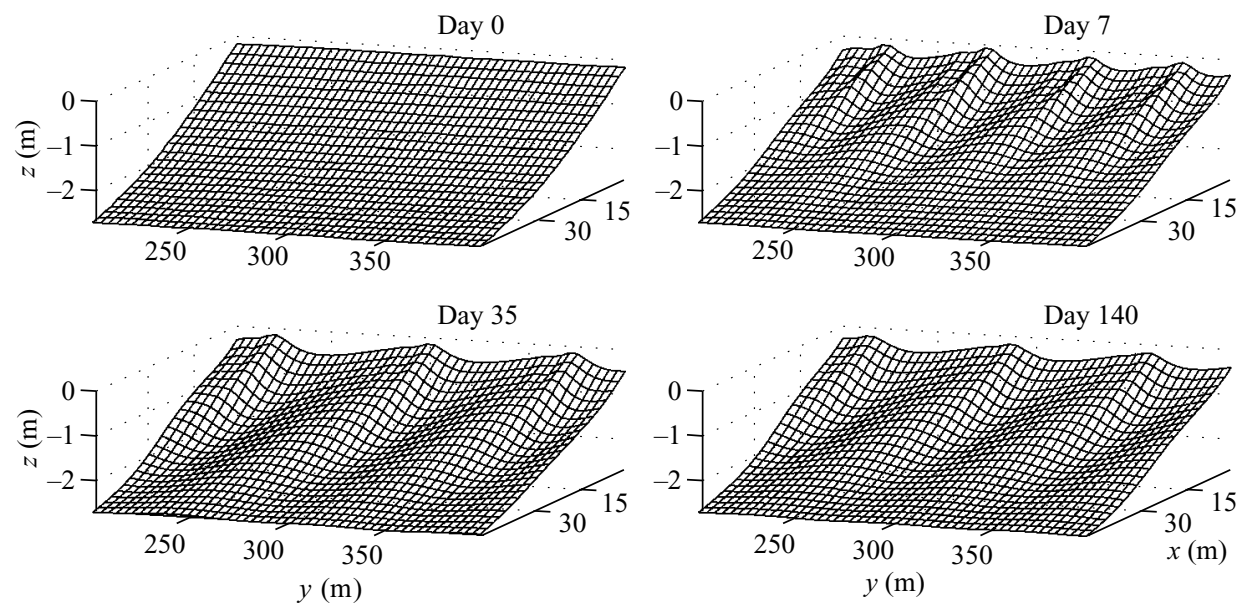

FIgURE 10 . CWS transport, $H_{r m s}=1.0 \mathrm{~m}, T=6 \mathrm{~s}, \theta=25^{\circ}$. Zoom of the total bathymetry during the formation, development and growth saturation of oblique up-current oriented bars.

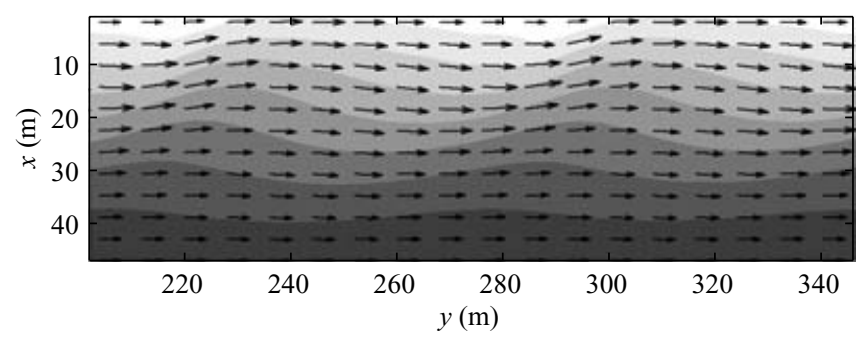

FIGURE 11. CWS transport, $H_{r m s}=1.0 \mathrm{~m}, T=6 \mathrm{~s}, \theta=25^{\circ}$. Final state (day 85). Bathymetric contours $\left(z_{b}\right)$ and circulation $(\boldsymbol{v})$ over up-current oriented bars. Shallowest areas are white and deepest areas are shaded.

of $\ln \left|\mathscr{H}\left(k_{l}, t\right)\right|$ shown in figure $9(f)$. This $30 \mathrm{~m}$ mode becomes dominant over the $25 \mathrm{~m}$ mode just after day 1 and competes with other modes. At day 3, it remains dominant until the end of the simulation. This plot allows us to estimate the growth rate of the finally dominant mode as $\sigma_{m} \simeq 1.6$ day $^{-1}$. Figure $9(\mathrm{~g})$ is in fact a transect of figure $9(a)$. The period $T_{m}$ of sand waves can be easily extracted from it. The final period, reached after day 5 , is $T_{m}=0.18$ day. The migration velocity may also be calculated as $c_{m}=\lambda_{m} / T_{m}$ and the values are consistent with figure $9(a)$.

\subsubsection{CWS transport, oblique waves (CWS)}

Figure 10 displays the evolution of the topography during the first 140 days. Only a partial view of the domain is shown in the $y$-direction $(200 \mathrm{~m}<y<400 \mathrm{~m})$. The time leading to the final saturated state seems very long, but at day 7 , the bars have already grown and have reached their final amplitude. At this time, they start to merge together so that their wavelength grows up to $73 \mathrm{~m}$, and at day 35 the bar system is very close to the final one at day 140 . Figure 11 shows the final morphology and hydrodynamics of this up-current bar system. As for the down-current bars, the longshore flow component $\left(|v| \simeq 0.8 \mathrm{~m} \mathrm{~s}^{-1}\right)$ is considerably larger than the cross-shore component ( up to $|u| \simeq 0.2 \mathrm{~m} \mathrm{~s}^{-1}$ ). The corresponding meandering is opposed to that in the case of down-current bars: the longshore current is deflected seaward over the crests and shoreward at the troughs. Again, this 'current refraction' is consistent 

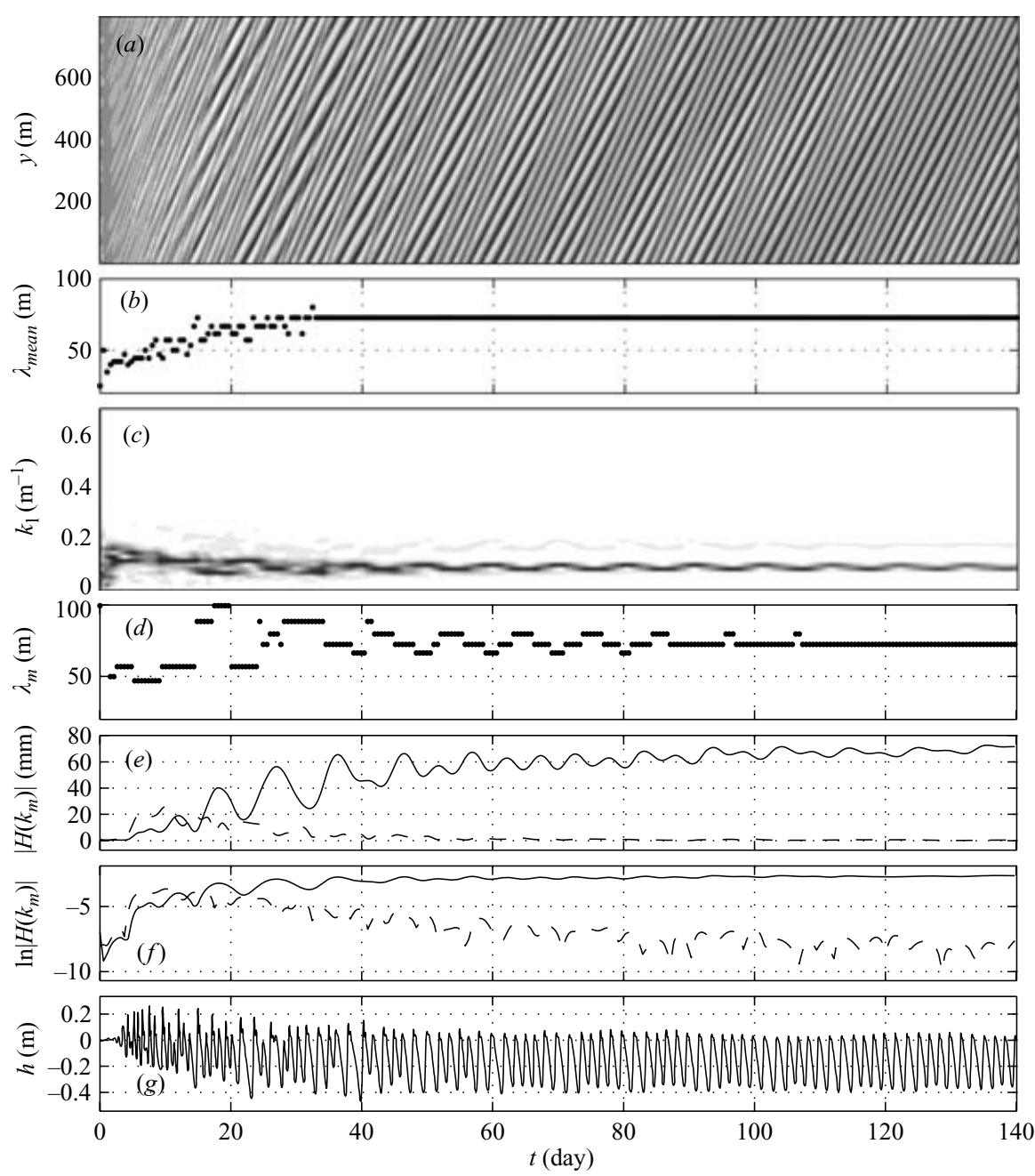

FIGURE 12. CWS transport, $H_{r m s}=1.0 \mathrm{~m}, T=6 \mathrm{~s}, \theta=25^{\circ}$. The graph description is the same as figure 9 but for $(e)$ and $(f), \lambda_{m}=2 \pi / k_{m}=50 \mathrm{~m}$ (dashed line), $\lambda_{m}=72 \mathrm{~m}$ (thick line).

with previous linear stability analysis (Ribas et al. 2003). In this case (constant wave stirring), it is similar to that of storm currents over shoreface-connected ridges on the inner continental shelf (Trowbridge 1995; Calvete et al. 2001) which occurs at a larger length scale. The steps observed in figure 10 are clearly recovered in figure $12(a)$. In particular, like the transverse bars and unlike the down-current oriented bars, these are visible on the total topography before having reached their final length. Complex dynamics in which the mean spacing $\lambda_{\text {mean }}$ (figure $12 b$ ) oscillates around $50 \mathrm{~m}$ occur because of splitting and merging of bars during the first 10 days. Merging eventually dominates so that the mean spacing increases up to about $\lambda_{\text {mean }}=72 \mathrm{~m}$ at day 35 and does not change anymore. Two states are observed (i) corresponding to the wavelength of about $\lambda_{\text {mean }}=50 \mathrm{~m}$ (from day 5 to day 10) and (ii) the final state (at day 140 , but very close to day 35 ). In contrast with the transverse bar case, state (i) corresponds to a predominant mode different to the final one (figure $12 c, d$ ). In this default case, we will assume the bar system has reached state (i) at day 7. We will denote the corresponding predominant modes for states (i) and (ii) by the subscripts 


\begin{tabular}{|c|c|c|c|c|c|c|c|c|c|c|c|c|c|c|c|c|}
\hline \multirow{2}{*}{ Case } & \multirow{2}{*}{ Mode } & \multicolumn{3}{|c|}{$H_{r m s} \nearrow$} & \multicolumn{4}{|c|}{$\theta \nearrow$} & \multicolumn{3}{|c|}{$T \nearrow$} & \multicolumn{5}{|c|}{$\gamma \lambda$} \\
\hline & & $A_{m}$ & $\lambda_{m}$ & $\sigma_{m}$ & $\lambda_{m}$ & $T_{m}$ & $\sigma_{m}$ & $c_{m}$ & $A_{m}$ & $T_{m}$ & $c_{m}$ & $A_{m}$ & $\lambda_{m}$ & $T_{m}$ & $\sigma_{m}$ & $c_{m}$ \\
\hline SVR-i & 1 & \multirow{4}{*}{$\pi$} & \multirow{3}{*}{$\pi$} & \multirow{4}{*}{$\pi$} & & & & & \multirow{4}{*}{$\searrow$} & & & \multirow{4}{*}{$\searrow$} & \multirow{4}{*}{$\nearrow$} & & \multirow{4}{*}{$\searrow$} & \\
\hline SVR-ii & & & & & $\pi$ & \multirow{3}{*}{$\searrow$} & \multirow{3}{*}{$\lambda$} & \multirow{3}{*}{$\lambda$} & & \multirow{3}{*}{$\searrow$} & \multirow{3}{*}{$\pi$} & & & & & \multirow{3}{*}{$\searrow$} \\
\hline \multirow{2}{*}{ CWS } & 1 & & & & & & & & & & & & & $\nearrow$ & & \\
\hline & 2 & & $\pi \searrow$ & & $\searrow$ & & & & & & & & & & & \\
\hline
\end{tabular}

TABLE 4. Main influence of the variable input parameters $\left(H_{r m s}, \theta, T\right.$ and $\left.\gamma\right)$ on the characteristics of the dominant modes. The symbol $\nearrow(\searrow)$ means that the corresponding characteristic increases (decreases) when the input parameter increases.

$m 1$ and $m 2$, respectively (table 3 ). The oscillating Fourier coefficients of these two modes which are the most energetic are displayed in figure 12(e,f) and show how a final equilibrium is hardly reached by the system. Because of these oscillations, the computed growth rates of these modes are just crude approximations.

\subsection{Parametric trends}

\subsubsection{Hydrodynamic parameters}

The influence of changing $H_{r m s}$ between 0.5 and $1.25 \mathrm{~m}$ has been investigated in all the cases (see table 4). For waves smaller than $0.5 \mathrm{~m}$ the morphological system is stable so that bars do not grow. For waves bigger than $1.25 \mathrm{~m}$, an extension of the cross-shore length of the domain is necessary. The dependence of bar formation on the wave height agrees with previous linear studies (Ribas 2004). Indeed, an increase of wave height implies larger wavelengths (both $\lambda_{m}$ and $\lambda_{\text {mean }}$ ) and a larger cross-shore span in direct relationship with a larger width of the surf-zone. It also implies larger bars in amplitude, but the shape (including the bar angle $\beta_{m}$ ) remains the same. The growth rate of the dominant mode also rises with rising wave height. In the case of oblique wave incidence, the period of bars keeps almost the same value, so the migration celerity decreases with an increasing wave height. For the two SVR cases, most of the dependence occurs between $H_{r m s}=0.5$ and $1 \mathrm{~m}$. This is also the case for the mode 1 of the CWS case (which is dominant before the merging of bars). In particular, $\lambda_{m}$ and $S_{m}$ increase by the factor 1.6 while $H_{r m s}$ doubles. Nevertheless, in the CWS case, the growth of wave height stimulates nonlinearities, so the merging of bars is much stronger for waves of $1.25 \mathrm{~m}$ than for waves of $1 \mathrm{~m}$ and this leads to bar spacing of $\lambda_{m 2}=130 \mathrm{~m}$ at the final state. In contrast, for waves of $0.5 \mathrm{~m}$ where bars do not merge, only mode 1 is present with a spacing of $\lambda_{m 1}=40 \mathrm{~m}$.

The wave angle is also a critical parameter for the formation of oblique bars (SVR-ii and CWS cases). Small wave incidence angles $\left(\theta<25^{\circ}\right)$ at the off-shore boundary have first been studied. By using the SVR transport, some cases lead to stability, but there is no clear threshold angle for the formation of down-current oriented bars. Where using the CWS transport, the threshold angle over which up-current oriented bars appear is about $\theta=20^{\circ}$. Final amplitude is only $6 \mathrm{~cm}$ and only mode 1 is present. For larger wave incidence angles $\left(25^{\circ} \leqslant \theta \leqslant 45^{\circ}\right.$ ) (table 4$)$, both for the SVR case and for CWS case (modes 1 and 2), the amplitude and the cross-shore span of the bar is not affected by the variation of the wave angle and the behaviour of the bars reveals some common tendencies: the increase of the wave angle implies the increase of $\sigma_{m}$, the decrease of $T_{m}$ and the increase of $c_{m}$. Nevertheless, while $\beta_{m}$ and $\lambda_{m}$ decrease in the SVR case, they have an opposite behaviour in the CWS case for the two modes. 
In all cases, variation of bar characteristics does not exceed $40 \%$ whereas wave angle increases $80 \%$.

The increase of wave period from 6 to $12 \mathrm{~s}$ has a minor effect on the shape of the bars, although the final amplitude of the bars tends to reduce, and, in the case of oblique wave incidence, the bar period decreases a little which implies an increase of the migration celerity (table 4).

\subsubsection{Bedslope parameter $\gamma$}

For each case, the effect of the bedslope parameter $\gamma$ has been investigated as indicated in table 3. For this range of $\gamma$, the results are summarized in table 4. For smaller values of $\gamma$, the bars grow too much and their tops tends to emerge from the water. The values of $\gamma$ leading to numerically stable computations are characterized by a ratio of maximum bar amplitude to total mean water depth, $h /(D+h)$, not larger than about 0.6 during the simulation. In other words, if this ratio exceeds 0.6 at some location at some time, the numerical model crashes. On the other hand, for larger values of $\gamma$, patterns do not appear since an increase of bedslope transport coefficient causes an increase in morphodynamic diffusivity producing a damping of the patterns. For the same reason, the linear stability theory would suggest than an increase of bedslope transport coefficient would cause an increase of the spacing and a decrease of growth rate and, thereby, a decrease of the final amplitude (weakly nonlinear stability analysis, Knaapen 2001). This behaviour is observed in the SVR cases, where $\lambda_{m}$ grows by $30 \%$ and $\sigma_{m}$ decreases by $70 \%$ between the two critical values of $\gamma$, whereas the amplitude decreases down to $3 \mathrm{~cm}$.

For the CWS case, the dynamics are more complicated. Indeed, mode 1 follows the same trends as described above and agrees with linear theory. Likewise, the amplitude and the growth rate of mode 2 also decrease with increasing $\gamma$. However, the final spacing $\lambda_{m 2}$ increases when $\gamma$ decreases. This is probably because a very low $\gamma$ leads to a strongly nonlinear regime where many wavelengths are allowed to interact, with the result that the dominant wavelength is a low subharmonic of the linearly dominant one. This increasing $\lambda_{m 1}$ and decreasing $\lambda_{m 2}$ with increasing $\gamma$ lead to a particular case for $\gamma=0.9$ where there is only one mode and bars do not merge.

More generally, the span of transverse bars remains about the width of the surfzone. For oblique bars, their angle is not affected, but their span grows when bars become larger. The migration velocity of oblique bars is also directly linked with the spacing: $c_{m}$ decreases when $\lambda_{m}$ increases, implying an even stronger reduction of $T_{m}$.

\section{Physical interpretation: growth and saturation}

\subsection{Local analysis of the growth}

According to the present modelling, the formation of the bars is due to a feedback between the morphology and the water flow which is positive - and dominant - only for certain shapes of the bars. Obviously, this is an output of the coupling between morphology and water motion through the sediment transport and it is as a result of sediment, water, momentum and energy conservation. However, the reasons why certain bar shapes grow and others do not, why this results in a particular longshore spacing, migration celerity and final amplitude are not straightforward. Nevertheless, some further insight may be gained by looking at the spatial distribution of the potential stirring, $\alpha / D$, as done in some previous studies (Falqués et al. 2000; Coco et al. 2002; Ribas et al. 2003). 
By using the sediment flux expression (2.6), the sediment conservation equation (2.4), reads

$$
(1-p) \frac{\partial h}{\partial t}+\nabla \cdot(\alpha \boldsymbol{v})-\nabla \cdot(\Gamma \nabla h)=0,
$$

where $\Gamma=\gamma \alpha u_{r m s}^{b}$ and where $\partial z_{b} / \partial t=\partial h / \partial t$ since $z_{b}^{0}$ is constant in time. Notice that the main difference with Caballeria et al. (2002) is that it is here assumed that, in general, $\alpha=\alpha\left(|\boldsymbol{v}|, u_{r m s}^{b}\right)$. Thus, if the sediment flux was for instance proportional to $|\boldsymbol{v}|^{m-1} \boldsymbol{v}$, the factor $|\boldsymbol{v}|^{m-1}$ would now be included in $\alpha$ in contrast with Caballeria et al. (2002). According to the water mass conservation (2.1),

$$
\nabla \cdot(\alpha \boldsymbol{v})=\nabla \cdot\left(\frac{\alpha}{D} D \boldsymbol{v}\right)=D \nabla\left(\frac{\alpha}{D}\right) \cdot \boldsymbol{v}-\frac{\alpha}{D} \frac{\partial D}{\partial t} .
$$

By inserting (4.2) in (4.1),

$$
(1-p) \frac{\partial h}{\partial t}+D v \cdot \nabla \Pi=\nabla \cdot(\Gamma \nabla h)+\Pi \frac{\partial D}{\partial t}
$$

is obtained, where $\Pi=\alpha / D$ stands for the potential stirring. The last term in this equation can be neglected because of the following. First, a reasonable upper bound for the stirring coefficient can be obtained from the SVR sediment transport in the case of $|\boldsymbol{v}| \sim 1 \mathrm{~m} \mathrm{~s}^{-1}$ as $\alpha \lesssim 0.001 \mathrm{~m}$ and, by assuming $D \gtrsim 0.1 \mathrm{~m}$, we can therefore assume $\Pi \lesssim 0.01$ (see also figure 3 ). Secondly, if the effects of infragravity waves on sediment transport are neglected, we can assume that the flow adjusts instantaneously to the slow bed changes (quasi-steady behaviour, see Caballeria et al. 2002). In this situation, $|\partial D / \partial t|=\left|\partial z_{s} / \partial t-\partial h / \partial t\right| \sim|\partial h / \partial t|$. Thus, the last term on the right-hand side in (4.3) is much smaller than the first one on the left-hand side and we can therefore use the following bottom evolution equation (BEE):

$$
(1-p) \frac{\partial h}{\partial t}=\nabla \cdot(\Gamma \nabla h)-D v \cdot \nabla \Pi .
$$

If the last term on the right-hand side is ignored, this is a diffusion equation for the bed perturbation, $h(x, y, t)$, and $\Gamma$ is hence referred to as morphodynamic diffusivity. Thus, without the second term on the right-hand side, the bed perturbations would just diffuse away (and propagate owing to advection effects because of the gradient in $\Gamma$ ), but instabilities could not develop. If morphodynamic instabilities occur, they should be induced by the second term. The condition for instability, is that this term be positive (causing $\partial h / \partial t>0)$ over the shoals $(h>0)$ and negative (causing $\partial h / \partial t<0)$ at the bed depressions $(h<0)$. This means that to have instability, the current must go against the gradients in potential stirring at the shoals and with the gradients in potential stirring at the troughs. Given a particular current $(\boldsymbol{v})$ and wave $\left(u_{r m s}^{b}\right)$ distributions, BEE allows for predicting and understanding the morphodynamic effect of such a hydrodynamic pattern. In particular, once the hydrodynamic pattern caused by a given morphology is known, BEE is useful for elucidating whether the morphological pattern will grow or decay or migrate. Notice that the flow enters the BEE not only explicitly through $\boldsymbol{v}$, but also implicitly via the dependence of $\alpha$ and $\Gamma$ upon $|\boldsymbol{v}|$ and $u_{r m s}^{b}$.

\subsubsection{Transverse bars}

Figure $13(a)$ shows the circulation pattern together with the contour lines of the potential stirring at the initial development of transverse bars $(t=3$ day). In the inner surf zone, the gradient in potential stirring is offshore directed so that, according to 


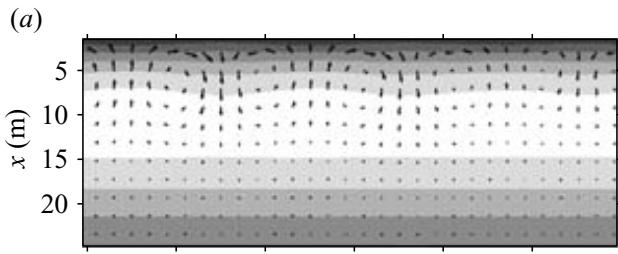

(c)
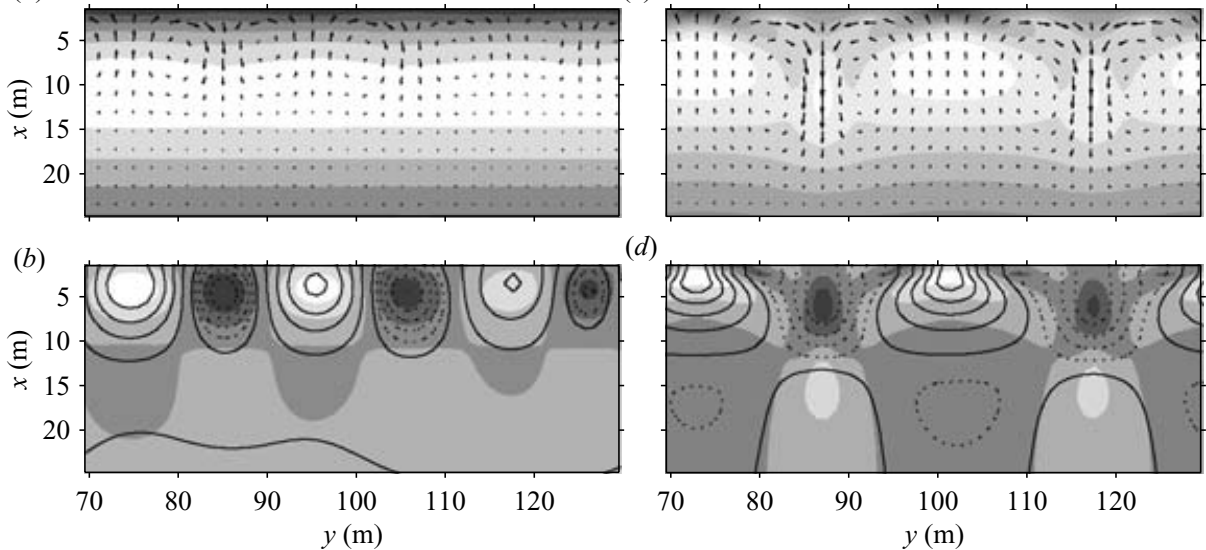

(d)

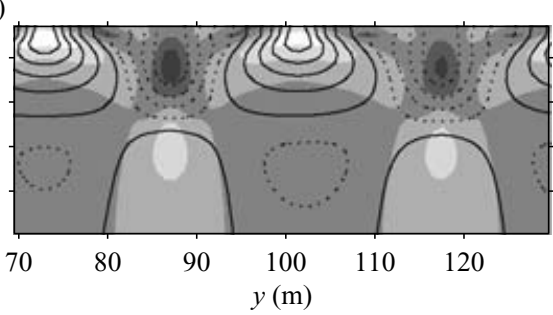

FIGURE 13. SVR transport, $H_{r m s}=1.0 \mathrm{~m}, T=6 \mathrm{~s}, \theta=0^{\circ}$. Left $(a, b)$ Initial state (day 3). $(c, d)$ Final state (day 12). $(a, c) \alpha / D$ (small values are shaded and large values are white) and current vectors. $(b, d) D v \cdot \nabla(\alpha / D)$ (negative values (accretion) are white and positive values (erosion) are shaded) and bottom perturbation $(h)$ contours (crests are straight lines, troughs are dotted lines).

the BEE, sediment deposition should occur at the onshore flow regions while erosion should occur at the rip current locations. This is fully corroborated by figure 13(b) where the perturbation in bed level is plotted. Furthermore, this type of flow pattern with onshore current at the shoals and offshore flow at the troughs is the one driven by the increased wave breaking over the shoals in comparison with the troughs (Falqués et al. 2000). The positive feedback is thus established leading to the formation of the bars. This is essentially similar to transverse bar formation in the earlier model of Caballeria et al. (2002).

The essentially new aspect in the present contribution is the saturation of the growth. Looking at the final state in figure $13(c, d)$, the gradient in potential stirring has now not only a cross-shore component, but also a longshore component. This is a consequence of the significant perturbations in water depth, $D$, but also of the sediment stirring by the currents, $\boldsymbol{v}$. Looking at the distribution of $D v \cdot \nabla \Pi$ on the bottom panel, it is seen that it still causes deposition over the shoals and erosion at the troughs. Thus, the saturation is reached not because the positive feedback between flow and morphology owing to the bedsurf coupling ceases, but because a balance between this effect and that from the downslope sediment transport is reached.

\subsubsection{Down-current oriented bars}

Figure 14(a) shows the contour lines of the potential stirring at the initial development of oblique bars ( $t=8$ day). The perturbation in the current, $(u, v-V(x))$, where $V(x)$ is the longshore current in the unperturbed state, is also shown. In figure $14(b)$, the bottom perturbation is displayed. In the unperturbed state the current runs alongshore and the gradient in $\Pi$ is cross-shore directed. As a result, for small amplitude bars the approximation

$$
D v \cdot \nabla \Pi \simeq D u \frac{\partial \Pi}{\partial x}+D V \frac{\partial \Pi}{\partial y}
$$

holds to first order in the perturbations. As can be seen in figure $14(a), \partial \Pi / \partial x>0$ at the inner surf zone and there is onshore flow over the crests, $u<0$. Therefore, the first 

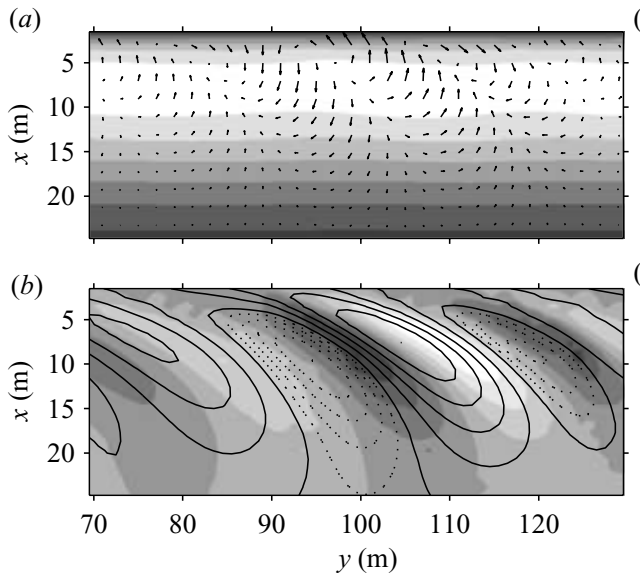

(c)

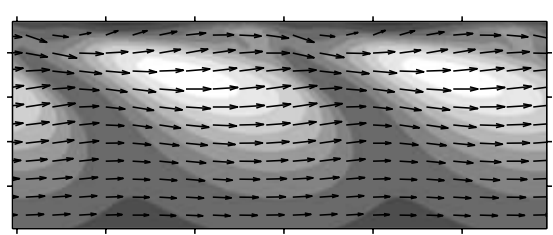

(d)

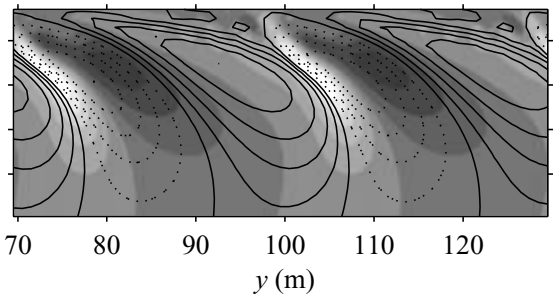

FiguRE 14. SVR transport, $H_{r m s}=1.0 \mathrm{~m}, T=6 \mathrm{~s}, \theta=25^{\circ} .(a, b)$ Initial state (day 8). $(c, d)$ Final state (day 14). The graph description is the same as figure 13, but vectors in (a) show only the current perturbation.

term on the right-hand side of (4.5) is negative. Looking at the longshore gradient in potential stirring it turns out that $\partial \Pi / \partial y<0$ somewhat downcurrent of the crests and $\partial \Pi / \partial y>0$ somewhat downcurrent of the troughs. Although this is hard to see in figure $14(a)$ where the total stirring is shown, it became apparent in plots where only the perturbation was displayed. Then, since $V>0$, this means that the second term on the right-hand side is also negative at the crests and somewhat downcurrent of them. The result is that $-D v \nabla \Pi$ has its maximum (minimum) value somewhat downcurrent of the crests (somewhat downcurrent of the troughs) and, according to the $\mathrm{BEE}$, this makes the bars grow and migrate downcurrent (figure 14b). The onshore veering of the current at the crests which is essential for bar growth is a consequence of both mass conservation and the increased breaking over the bars (Ribas et al. 2003). In figure 14(c) the total current, $v$, is shown instead of the perturbation. The maximum value of $-D v \cdot \nabla \Pi$ is located at the lee of the bar, indicating downcurrent migration without growth (figure $14 d$ ). Nevertheless, this is hard to ascertain just looking at the figure and, moreover, the downslope transport has also some influence.

\subsubsection{Up-current oriented bars}

In general terms, the initial development of up-current oriented bars described in the present modelling is consistent with the linear stability predictions of Ribas et al. (2003). The use of the same sediment transport formulation and unbarred beach profile implies the same structure of the potential stirring, $\Pi$, i.e. seaward decreasing. Under such conditions, for zero or small-wave incidence angle, the beach system is stable. For larger wave incidence angle, up-current oriented bars emerge with a shape which is very similar to the linear mode.

Similarly to the case of downcurrent oriented bars, the explanation for the initial formation of the bars can also be given in the present context on the basis of the approximation in (4.5) which is now valid too. However, the gradient in potential stirring has now an opposite direction (shoreward) (figure 15a). Therefore, the formation of the bars also requires an opposite direction for the cross-shore flow component, seaward on the bars and shoreward on the troughs, which is met only for up-current oriented bars. Therefore, these are the emerging types of bar. 

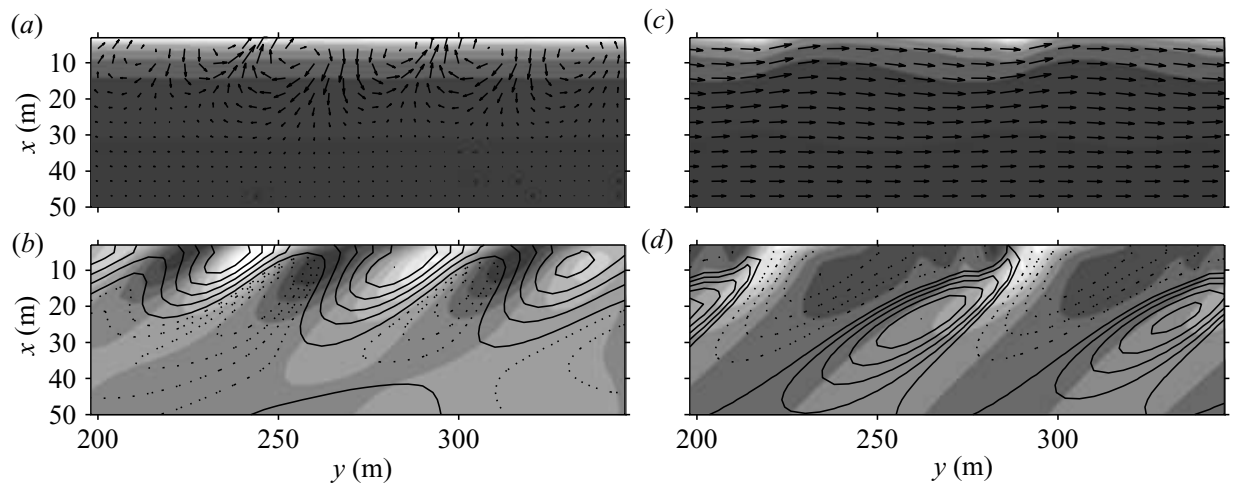

FIGURE 15. CWS transport, $H_{r m s}=1.0 \mathrm{~m}, T=6 \mathrm{~s}, \theta=25^{\circ}$. $(a, b)$ Initial state (day 5). $(c, d)$ Final state (day 85$)$. The graph description is the same as figure 14.

Although figure $15(b)$ indicates the growth and downcurrent migration of bars, looking at figure $15(a)$ it is difficult to see clearly the appropriate matching of the cross-shore flow with the bar crests and troughs. Nevertheless, an analysis (not shown) of the effect of the two terms of the right-hand side of (4.5) reveals that $D V \partial \Pi / \partial y$ is the largest one, but only causes down-current migration. In contrast, $D u \partial \Pi / \partial x$ is smaller and produces growth of the bars along with a slight up-current migration.

The final state is displayed in figure $15(c, d)$. From the accretion/erosion pattern, the down-current migration is clearly apparent. Yet, again, it is hard to see from it whether the saturation has been really achieved.

\subsection{Global analysis of the saturation}

Although previous morphodynamic modelling has occasionally predicted saturation of the growth of the emerging features, the analysis of the physical mechanisms leading to it was only based on indications given by local analysis at some particular locations (see, for instance, Calvete \& de Swart 2003) so that a thorough study was lacking. To this end, we develop here a method to analyse the saturation of the bars which is based on their dynamics on the whole domain. According to (4.1) or to the approximated BEE (4.4), the tendency to the growth (or decay) of bars by the bedflow/bedsurf couplings can be measured by

$$
\mathscr{P}=-\int_{0}^{L_{y}} \int_{0}^{L_{x}} h \nabla \cdot(\alpha \boldsymbol{v}) \mathrm{d} x \mathrm{~d} y \simeq-\int_{0}^{L_{y}} \int_{0}^{L_{x}} h D \boldsymbol{v} \cdot \nabla \Pi \mathrm{d} x \mathrm{~d} y
$$

that will hereinafter be called the 'production term'. Similarly, the 'damping term' due to the diffusive effect of downslope sediment transport is defined as

$$
\Delta=\int_{0}^{L_{y}} \int_{0}^{L_{x}} h \nabla \cdot(\Gamma \nabla h) \mathrm{d} x \mathrm{~d} y,
$$

which is typically negative. The precise meaning of both terms can be illustrated by considering the case of a topographic wave given by $h(x, y, t)=\varphi(t) f\left(x, y-c_{m} t\right)$, that is, a wave which propagates alongshore with celerity $c_{m}$, grows or decays according to $\varphi(t)$, but keeps a constant shape given by $f(x, y)$. It is assumed that $f$ is $L_{y}$ periodic with respect to $y$ and that the topographic wave is confined within the longshore strip 
$0<x<L_{x}$. Then, a measure of its amplitude is its $L 2$-norm, defined as

$$
\|h\|=\left(\frac{1}{L_{x} L_{y}} \int_{0}^{L_{y}} \int_{0}^{L_{x}} h^{2} \mathrm{~d} x \mathrm{~d} y\right)^{1 / 2} .
$$

Because of the $L_{y}$ periodicity of $f$, the time derivative of $\|h\|^{2}$ is:

$$
\frac{\mathrm{d}}{\mathrm{d} t}\|h\|^{2}=\frac{2}{L_{x} L_{y}} \int_{0}^{L_{y}} \int_{0}^{L_{x}} h \frac{\partial h}{\partial t} \mathrm{~d} x \mathrm{~d} y=\frac{2}{L_{x} L_{y}} \frac{\varphi^{\prime}}{\varphi}\|h\|^{2} .
$$

According to the last equation, in the case of an exponential growth or decay, $\varphi(t)=\mathrm{e}^{\sigma t}$ with $\sigma \in \mathfrak{R}$, the growth rate can be evaluated, independently of the migration, as:

$$
\sigma=\frac{1}{\|h\|^{2}} \int_{0}^{L_{y}} \int_{0}^{L_{x}} h \frac{\partial h}{\partial t} \mathrm{~d} x \mathrm{~d} y .
$$

Now, by substituting $\partial h / \partial t$ using (4.1) or (4.4) into (4.7), it is found that the growth rate is directly related to the production and damping terms by

$$
\sigma=\frac{1}{\|h\|^{2}}(\mathscr{P}+\Delta) \text {. }
$$

Coming back to the general case of the solutions of our model equations, the instantaneous growth rate which is defined by (4.8) will decide the tendency to grow or to decay. Notice that for the initial formation of the bars, $\mathscr{P}$ will be larger than $-\Delta$ and they both will grow as $\|h\|^{2}$, since $\sigma$ will be approximately constant according to linear stability theory. Once the bars reach a significant amplitude, these trends will no longer apply and saturation will occur when $\sigma=0$, i.e. $\mathscr{P}=-\Delta$. Notice that this criterion is necessary but not sufficient, indeed, owing to the change of shape of the bars which may be the result of interactions of various modes, this criterion may be satisfied more than once during the evolution whilst the saturation is not reached. Thus, this prohibits a prediction of the moment of saturation.

\subsubsection{Transverse bars}

To find out why the balance between those two tendencies occurs, it is illustrative to analyse the trends in the production term, $\mathscr{P}$, and the damping term, $\Delta$, when the bar amplitude measured by $\|h\|$ increases. Figure $16(a)$ shows $\mathscr{P}^{1 / 2}$ and $(-\Delta)^{1 / 2}$ as a function of $\|h\|$. Both increase approximately linearly at the initial stages and $\mathscr{P}$ is larger than $-\Delta$ as the bars grow significantly. Nevertheless, the increase in $-\Delta$ with $\|h\|$ becomes larger than the increase in $\mathscr{P}$ so that both curves cross each other for $\|h\|=0.018 \mathrm{~m}$. At this point, the bar growth stops and the final balance is reached. This behaviour is clearly seen plotting the difference between production and damping, $\mathscr{P}+\Delta$, as a function of bar amplitude, $\|h\|$ (figure $16 d$ ). This difference is seen to increase from zero to a maximum at $\|h\|=0.012 \mathrm{~m}$ and then to decrease to $\|h\|=0.018 \mathrm{~m}$ where it vanishes. This maximum of $\mathscr{P}+\Delta$ characterized by a zero derivative is retrieved in figure $17(a)$ when the curve of $\mathrm{d} \mathscr{P} / \mathrm{d}\|h\|$ and $d(-\Delta) / \mathrm{d}\|h\|$ cross each other. Even beyond this point, both $\mathscr{P}$ and $-\Delta$ keep on increasing their growth rate until the final equilibrium, although $-\Delta$ do it more vigorously.

\subsubsection{Down-current bars}

Comparison of figure $16(b)$ with figure $16(a)$ shows three significant differences between down-current oriented bars and transverse bars. At the initial stage, the production and damping terms are closer for down-current bars (i). At the final stage, 

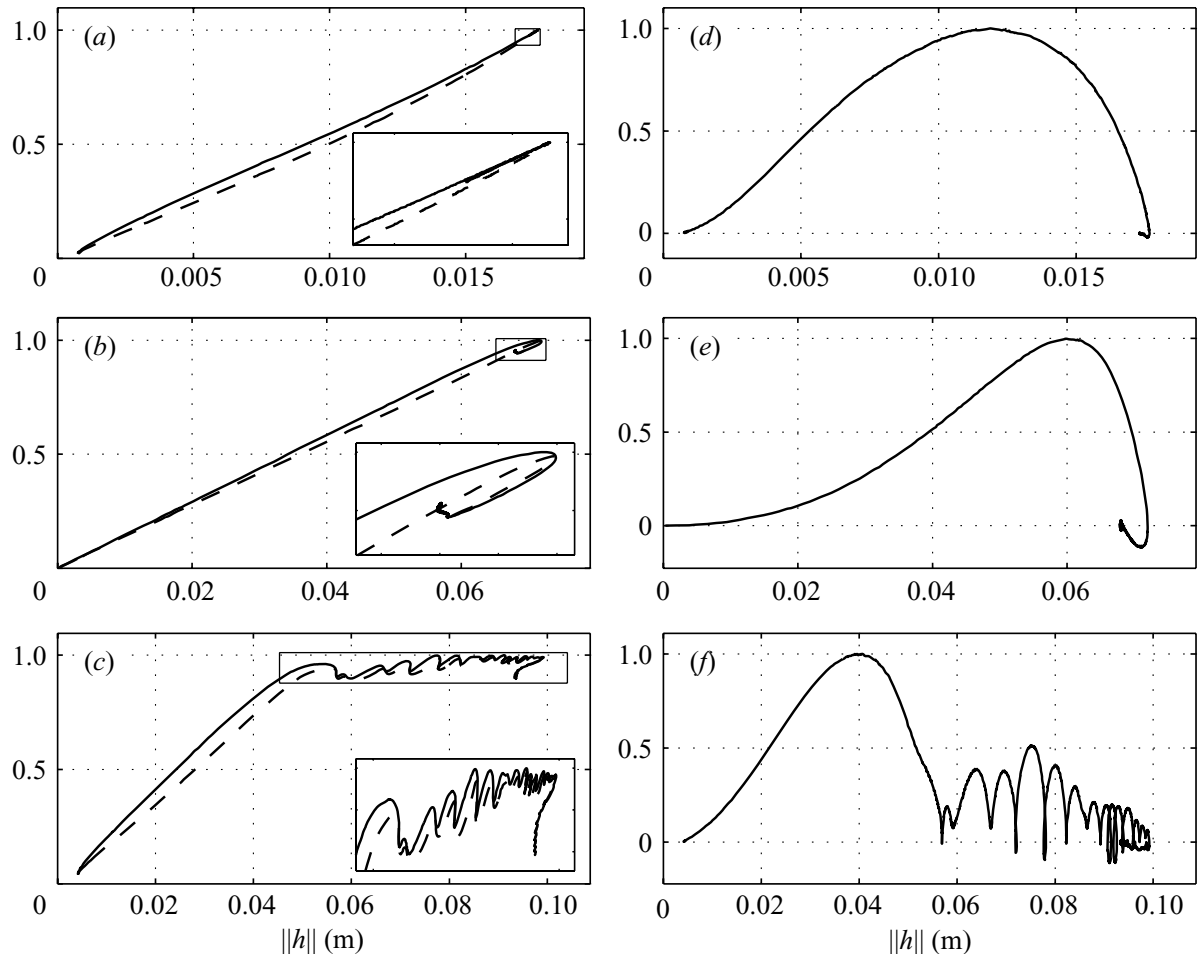

FIGURE 16. $H_{r m s}=1.0 \mathrm{~m}, T=6 \mathrm{~s} .(a-c)$ Square root of the - production and ---, damping terms as a function of $\|h\| .(d-f)$ Difference between production and damping, $(\mathscr{P}+\Delta)$ as a function of $\|h\| .(a, d)$ SVR transport, $\theta=0^{\circ},(b, e)$ SVR transport, $\theta=25^{\circ},(c, f)$ CWS transport, $\theta=25^{\circ}$.
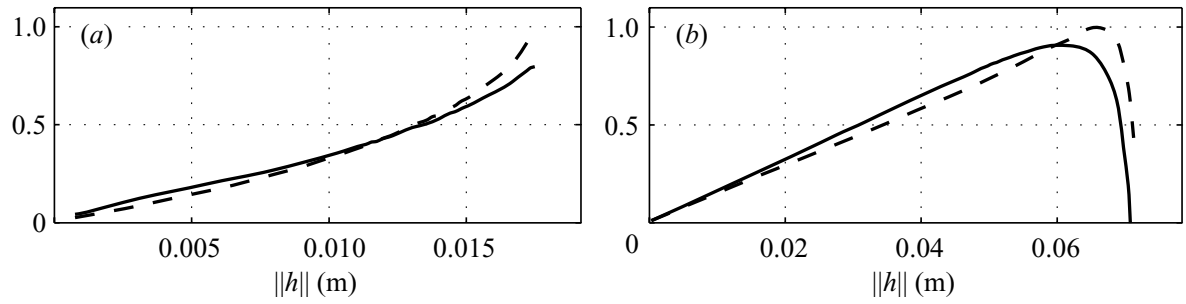

FIGURE 17. SVR transport, $H_{r m s}=1.0 \mathrm{~m}, T=6 \mathrm{~s}$. Derivatives of,$- \mathrm{d} \mathscr{P} / \mathrm{d}\|h\|$ and,$----\mathrm{d} \Delta / \mathrm{d}\|h\|$ as a function of $\|h\| .($ a $) \theta=0^{\circ},(b) \theta=25^{\circ}$.

both terms moderate its growth and the instability source do it more drastically (ii) and before reaching the final equilibrium the amplitude of bars decreases (iii). Claim (i) is readily seen from the smaller initial slope of the $\mathscr{P}+\Delta$ curve in figure 16(e) in comparison to figure $16(d)$. The final loop in the $\mathscr{P}+\Delta$ curve in figure 16(e) corroborates claim (iii). Claim (ii) follows by comparing figure 16(b) with figure 16(a), but it becomes most apparent by looking at figure $17(b)$ where it is seen that $\mathrm{d} \mathscr{P} / \mathrm{d}\|h\|$ start to decrease earlier than $\mathrm{d}(-\Delta) / \mathrm{d}\|h\|$ and do it more strongly.

\subsubsection{Up-current bars}

As shown in figure $16(c, f)$ it is found that the behaviour of this kind of bar is more complicated than the others. This is because of the merging of individual bars 
(a)

(b)

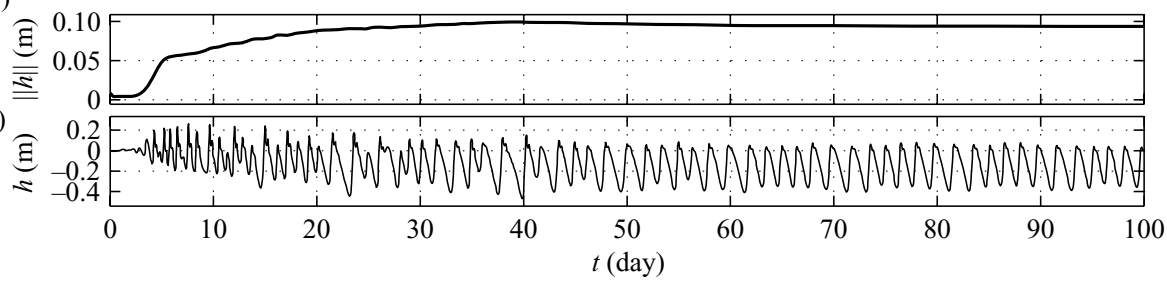

Figure 18. CWS transport, $H_{r m s}=1.0 \mathrm{~m}, T=6 \mathrm{~s}, \theta=25^{\circ}$. Time evolution of $(a)\|h\|$ and $(b) h(10,22.5)$.

occurring when bar amplitude is significant. It turns out that a first balance between production and damping appears when $\|h\| \approx 0.05 \mathrm{~m}$ before day 7 (figures 18 and $16 c, f)$. This first saturation of the growth corresponds to the saturation of mode 1 described in $\S 3.2 .3$. Nevertheless, after day $7,\|h\|$ resumes its growth and keeps growing until nearly $0.1 \mathrm{~m}$ at day 40 (figure $18 a$ ). This increase in $\|h\|$ is not due to an increase of bar amplitude which remains nearly constant (figure $18 b$ ), but to the increase of cross-shore span because of bar merging. Figure $16(c, f)$ illustrates this strongly nonlinear behaviour with intriguing oscillations which begin with the first (unsteady) balance between production and damping and end up with the balance leading to the final saturated bars (mode 2 in $\S 3.2 .3$ ).

\section{Discussion}

\subsection{Saturation of the growth}

While the linear stability analysis shows the tendency of the morphodynamic system to produce bars, it does not actually prove that such bars should be observed in nature. It could be that if the nonlinearities are included, the model prediction for bar amplitude would be exceedingly small. In such a case, the corresponding instability mechanism could not be considered as the origin of the observed bars. Thus, the present study can be considered as the first proof that shore-oblique bars can actually emerge by self-organization of the coupling between waves, currents and morphology via sediment transport. In the case of transverse bars, there was the earlier nonlinear stability analysis by Caballeria et al. (2002), but that study had the shortcoming that the model could not describe the saturation of the bar growth. This has now been overcome and finite-amplitude shore-transverse and oblique sand bars have been modelled for the first time.

The saturation is obtained as a balance between the down-slope sediment transport and the positive feedback between flow and morphology which is responsible of the initial formation of the bars. Both effects grow proportionally to bar amplitude at the initial stage, the instability term being somewhat stronger. The process by which equilibrium is eventually reached is complex and sometimes shows a number of oscillations which reveals that the criterion for the saturation is not sufficient. Essentially, two different scenarios are found for the saturation: (i) the damping term accelerates its growth so that it eventually balances the instability source or (ii) the instability source weakens so that it becomes balanced by the damping. This means that saturation occurs either because the finite-amplitude shape of the bars enhances downslope transport (i) or weakens the instability mechanism (ii). Notice that for some experiments, there are still interactions between several modes even if the measure of the amplitude $(\|h\|)$ is already stabilized and the criterion of the 
global saturation is verified. This state could be interpreted as a dynamic equilibrium state.

The final balance is very sensitive to the $\gamma$ parameter of the down-slope transport. Typically, formation of finally equilibrated bars takes place only for a relatively narrow range of values. Values that are too large lead to stability of the alongshore uniform topography while values that are too small lead to overflow of the numerical model as the bars grow too much and their top tends to grow almost up to the mean sea surface. The saturation could occur in the latter case owing to processes related to very shallow water over the bars not described by the present model. The values of $\gamma$ leading to numerically stable computations are characterized by a ratio of maximum bar amplitude to total mean water depth not larger than about 0.6. Even if the model does not resolve the individual waves, this ratio corresponds to the situation where the water depth at the troughs of the waves would be roughly zero. Thus, this numerical limitation does not pose any physical limitation on the model.

\subsection{Characteristics of the bars}

In line with previous linear stability analysis (Ribas et al. 2003), the different types of bar emerging in each situation depend mainly on the cross-shore profile of the potential stirring, $\alpha / D$, and on wave approach angle. In the case of an offshore decreasing potential stirring (CWS transport), for zero to moderate wave angle, the alongshore uniform morphology is stable. For quite oblique wave incidence (above $\theta \approx 17^{\circ}$ ), up-current oriented bars emerge. The typical growth times are $2-4$ days. The amplitude ranges between $0.05 \mathrm{~m}$ and $0.5 \mathrm{~m}$, increases with $H_{r m s}$ (between 0.5 and $1.25 \mathrm{~m}$ ) and decreases with increasing bedslope transport coefficient, $\gamma$. The longshore spacing increases with wave angle and has a complex behaviour with $\gamma$, ranging between 60 to $130 \mathrm{~m}$. For oblique wave incidence the bars migrate down-current with a celerity between 30 and $70 \mathrm{~m} \mathrm{day}^{-1}$ that increases drastically with wave angle from $17^{\circ}$ to $35^{\circ}$. The bar dynamics are coupled to a meandering of the longshore current with offshore flow over the bars and onshore flow at the troughs. The magnitude of the cross-shore component is about $0.3 \mathrm{~m} \mathrm{~s}^{-1}$ while the longshore component is about $0.9 \mathrm{~m} \mathrm{~s}^{-1}$ for waves of $H_{r m s}=1 \mathrm{~m}$. The angle of the bars with the shore-normal ranges from $\beta_{m}=42^{\circ}$ to $67^{\circ}$.

In the case of an offshore increasing potential stirring across the inner surf zone up to a maximum and an offshore decreasing potential stirring beyond this point (SVR transport), transverse bars form in the case of normal wave incidence. The bars have an amplitude between 0.08 and $0.19 \mathrm{~m}$ which increases with wave height. The longshore spacing is about $30 \mathrm{~m}$, slightly increasing with $H_{r m s}$. The cross-shore length increases too with $H_{r m s}$ and ranges between 9 and $12 \mathrm{~m}$. The existence of the bars is clearly linked to a horizontal circulation with jet-like rip currents in the troughs up to $0.52 \mathrm{~m} \mathrm{~s}^{-1}$. A typical growth time is a couple of days. Their formation mechanism is similar to that described in Caballeria et al. (2002). Differences arise due only to a different description of hydrodynamics which consider irregular waves, but do not account for wave refraction by the growing bars. Anyhow, the mean flow has the same structure, i.e. onshore (offshore) directed on the bars (at the troughs), and this is the essential characteristic that makes the bars grow.

With the same structure of the potential stirring that led to the formation of transverse bars, but in the case of oblique wave incidence, downcurrent oriented bars emerge. The amplitude is about $0.30 \mathrm{~m}$ and the longshore spacing increases with wave height from 19 to $43 \mathrm{~m}$. The angle of the bars with the shore-normal increases too from $\beta_{m}=35^{\circ}$ to $60^{\circ}$. The typical growth time is about 2 days. The bars migrate 
downcurrent at celerities which range between 100 and $260 \mathrm{mday}^{-1}$ and increase with wave height, wave incidence angle and wave period. They are also linked to a meandering of the longshore current, this time with onshore flow over the bars and offshore flow at the troughs. The magnitude of the cross-shore flow component is about $0.3 \mathrm{~m} \mathrm{~s}^{-1}$ with a longshore component of $1 \mathrm{~m} \mathrm{~s}^{-1}$.

\subsection{Initial characteristics versus finite-amplitude characteristics}

An important limitation of the explanations of pattern formation by self-organization is that they are sometimes based on linear stability analysis. The question then arises as to whether the shape, length scale and migration celerities predicted by linear stability analysis actually applies to the finite-amplitude features which should be comparable to the corresponding patterns in nature. The present study sheds some light on this issue and it turns out that the answer is sometimes 'yes' and sometimes 'no'. For instance, the final longshore spacing of transverse bars and down-current oriented bars is similar to the initial one, whereas it is significantly larger for upcurrent oriented bars, $72 \mathrm{~m}$ compared to $50 \mathrm{~m}$ for the default parameter set. Both for up-current and down-current oriented bars, the initial and final migration celerities are different. For up-current bars, the final celerity is smaller than the initial, $43 \mathrm{~m} \mathrm{day}^{-1}$ compared to $71 \mathrm{~m} \mathrm{day}^{-1}$. In contrast, for down-current bars it is the other way around, a final celerity of $167 \mathrm{~m} \mathrm{day}^{-1}$ which is larger than the initial one, $150 \mathrm{~m} \mathrm{day}^{-1}$ (for the default parameter set). Regarding the shape, linear stability can only predict sinusoidal patterns where crests and troughs are symmetrical. Consistently, onshore and offshore flow with the same intensity is equally distributed along the coast. This is clearly not so for the finite-amplitude features. For instance, transverse bars show an asymmetry of crests and troughs which is different close to the shoreline or far from it. Close to the shoreline, the crests are narrow and the troughs wider, whereas offshore the shoals are wider and the rip channels narrower. Very remarkable is the asymmetry between offshore flow (rip currents) and onshore flow. The former is strong and narrow whereas the latter is wider and weaker in accordance to common observations on rip-current systems (Short 1999). In the case of oblique wave incidence where the bars migrate down-current, the longshore sections of the bars have the typical asymmetry, the lee being steeper than the stoss. In all cases, this final asymmetric behaviour of the bars and of the current is crucial since we saw the final spatial structure of the topography and of the flow is responsible for the saturation of the growth. Indeed, in each case of non-saturation (when overflow occurs) we noticed the bars had kept its linear structure.

The overall shape in plan view of the transverse and up-current bars does not differ much between the initial and the final stages. However, the initial shape of downcurrent bars turns out to be very linear whereas for large amplitude the down-current bars tend to curve backward with their offshore tip veering up-current. Thus, the final conclusion is that small-amplitude analysis can reliably predict only the order of magnitude of the longshore spacing and migration celerity along with the overall shape, but not the details of it.

\subsection{Comparison with observations}

Model results can be compared with experimental data only in a very limited way. First, the model is at present very idealized and the main purpose was just to show that transverse/oblique bars of finite amplitude could emerge from morphodynamic instabilities of the surf zone and showed a realistic nonlinear dynamics. Secondly, although this type of bar is often observed in nature, field data sets on their 
generation involving morphological evolution along with hydrodynamics are scarce and incomplete. Unfortunately, a systematic field study such as van Enckevort et al. (2004) for crescentic bars is lacking for transverse/oblique bars. Thus, we will use here just an overall comparison between model results and observed bars and it will be sufficient for our purposes to refer to the systematic summary of existing observations in Ribas et al. (2003). Additional information not included in that paper can be found in Lafon et al. (2002) and Castelle (2004).

Shore-attached bars in nature can be both perpendicular or oblique to the coastline. According to Ribas et al. (2003), the most common orientation in the latter case is down-current, but the up-current orientation can also exist. In this respect, the model is successful in describing the formation of the three types of bar. However, the conditions on the potential stirring necessary to produce the different types cannot be checked through the field data description in the existing literature. It is nevertheless likely that the most common situation (for intermediate beach states where the infragravity wave energy is not dominant in the inner surf zone) is an offshore increasing stirring function through the inner surf zone for which the model predicts either transverse bars or down-current oriented bars according to wave angle. The shape of the bars in the model is overall representative of the ensemble of observed shapes for such bars. The model reproduces the observed asymmetry, the downcurrent flank being steeper than the up-current flank. The longshore spacings of shore-attached bar systems in the model range between 30 and $75 \mathrm{~m}$, i.e. within the range of the observed spacings which is between 12 and $760 \mathrm{~m}$ (Ribas et al. 2003; Castelle 2004). It seems that the spacing is correlated with the width of the surf zone and the large scatter in observed spacings is probably related to differences in surf zone width. Because of the use of Rayleigh distributed waves it is difficult to define the surf zone width in the model, but we can define it as the distance from the shore to the location of maximum wave dissipation which is about $15 \mathrm{~m}$. Thus, the ratio spacing/surf zone width would be about $2-5$, which is comparable to the values reported in the literature. The typical growth times of a couple of days in the model are not in disagreement with the scarce data which point to a formation time ranging between one and a few days. The currents associated with the presence of the bars are also consistent with observations. In the case of transverse bars, strong and narrow rip currents form in the troughs and wide and weaker onshore flow over the shoals. The onshore (offshore) veering of the longshore current over the bars (troughs) is also very typical of down-current oriented bars. Less well known is the observed flow pattern in the case of up-current oriented bars. In this case, the meandering of the longshore current in the model can be compared to the observed one in the case of storm-driven currents over the shoreface-connected ridges on the inner continental shelf and they show correspondence (Trowbridge 1995). As in nature, bars migrate down-current in the model. The computed celerities range between 30 and $70 \mathrm{~m} \mathrm{day}^{-1}$ for up-current oriented bars and between 100 and $260 \mathrm{~m} \mathrm{day}^{-1}$ for down-current oriented bars. In contrast, observed celerities reported in the literature range from a few metres up to $40 \mathrm{~m} \mathrm{day}^{-1}$ (Lafon et al. 2002; Ribas et al. 2003) so that it seems that the model tends to overpredict the migration speed. This, however, deserves further attention. First of all, the measured migration speeds are very often an average over several days, weeks or even months, during which the wave energy and direction may change substantially and may not be representative of a sustained forcing with constant wave conditions. For instance, Lafon et al. (2002) reported a mean southerly migration of the bar system along the French Atlantic coast of about $2.4 \mathrm{~m} \mathrm{day}^{-1}$ during the summer of 1989 . However, there are periods of either very low 
wave energy or nearly normal wave incidence. Thus, this value is not representative of waves incident all the time with a large angle with the shore-normal as in the model. For example, the measurements taken with a much higher frequency by Konicki \& Holman (2000) gave celerities up to $40 \mathrm{mday}^{-1}$. A second aspect is that bar celerity depends largely on its size, both in the model and in nature (Falqués et al. 1996), the larger the bars, the more slowly they move. The down-current bars in the model have quite a small spacing $(\sim 30 \mathrm{~m}$, at the lower bound of the range of observed spacings) and this probably causes their large celerity. In contrast, the up-current bars which are larger have celerities that are roughly consistent with those observed by Konicki \& Holman (2000).

\subsection{Model simplifications}

The increased (decreased) wave breaking over the shoals (troughs) causes gradients in set-up and mean flows. When a longshore current is present, the alongshore nonuniform topography also triggers gradients and meandering of the current. This is the main feedback mechanism of the morphology onto the hydrodynamics in the model. The morphodynamic loop is closed when a sediment transport parameterization is added to this framework. The two parameterizations used in the present study are suitable for the sediment transport driven by the longshore current and/or rip-current circulation and consistently disregard the weaker cross-shore transport due solely to the waves. Importantly, a preference for down-slope transport is included. These are the essential ingredients of the model that are shown to lead to the formation of self-organized shore-transverse or oblique bars of finite amplitude that compare reasonably well with observations.

Some aspects, however, deserve further attention. Wave refraction by the alongshore non-uniform topography has been considered only in a simplified way. Although Caballeria et al. (2002) pointed out that it was essential for the onshore current over the crests of the transverse bars which in turn is essential for its growth, our computations have shown that this current may exist even without wave refraction. Apart from refraction, the essential difference between that model and the present one is that irregular waves are now considered. Therefore, the importance of wave refraction could probably be restricted to the case of regular waves. It is nevertheless advised that future work should include a description of wave refraction over the bars which is suitable for finite-amplitude topographic features. This would allow us to check its influence which is expected, however, to be limited. This description should also include wave diffraction which has not been accounted for in the present model. While refraction tends to concentrate wave energy over the shoals, diffraction tends to diffuse it away. Thus, both effects are expected to oppose each other and their analysis is an interesting issue for future research.

Finally, the down-slope sediment transport is not yet very well known and a rather crude description has been adopted here. The sensitivity of the model to the slope coefficient, $\gamma$, has, however, pointed out that down-slope transport may be crucial for the saturation of bar growth and for finite-amplitude bar properties. Thus, more attention should be paid in future to gravitational down-slope transport.

\section{Conclusions}

The differential wave breaking over shoals and troughs (bedsurf effect) along with the gradients and meandering caused on the longshore current (bedflow effect) may cause the growth of self-organized shore-attached transverse or oblique bars on an 
unbarred beach. Oblique bars in the model may be either down-current oriented or up-current oriented depending on the cross-shore profile of the ratio stirring to water depth. This is largely in line with previous linear stability studies, but the new aspect is now that the gravitational down-slope sediment transport may stop the growth at realistic bar amplitudes. A global method for analysing the saturation of bar growth is developed and it is found that the final balance between the effects of that transport and the bedsurf/bedflow instabilities occurs because the finite-amplitude shape of the bars either enhances downslope transport or weakens the instability mechanism. The onset of the saturation allows us to explore the nonlinear dynamics of the bars which include merging of individual bars, asymmetry of the longshore shape, occurrence of jet-like rip currents and oscillatory behaviour (dynamic equilibrium). The final overall shape of the bars in plan view is similar to the initial one, although some details may be substantially different. The final and the initial longshore spacings and migration celerities are of the same order of magnitude, but differences up to a factor of 2 may arise.

This paper is funded by the Ministerio de Ciencia y Tecnologia of Spain through the PUDEM project under contract REN2003-06637-C02-01/MAR and through the 'Ramón y Cajal' contract of D. Calvete. This paper is also based on work in the HUMOR project, sponsored by the EU under contract MAS3-CT97-0081. The work of R. G. was supported by the Catalan Government with his IQUC grant. Their support is gratefully acknowledged. We want to thank the three anonymous referees for their useful comments.

\section{REFERENCES}

Ashton, A., Murray, A. B. \& Arnault, O. 2001 Formation of coastline features by large-scale instabilities induced by high-angle waves. Nature 414, 296-300.

Bailard, J. A. 1981 An energetics total load sediment transport model for a plane sloping beach. J. Geophys. Res. 86, 10938-10954.

Barcilon, A. I. \& LaU, J. P. 1973 A model for formation of transverse bars. J. Geophys. Res 78, 2656-2664.

Battjes, J. A. 1975 Modeling of turbulence in the surfzone. In Proc. Symp. Model. Tech., pp. 1050-1061. ASCE, San Francisco, USA.

Blondeaux, P. 1990 Sand ripples under sea waves. Part 1. Ripple formation. J. Fluid Mech. 218, $1-17$.

Caballeria, M. 2000 Self-organization in the nearshore: shear waves, transverse and crescentic bars. PhD thesis, Appl. Physics Dept, Univ. Politècnica de Catalunya, Barcelona, Spain.

Caballeria, M., Coco, G., Falqués, A. \& Huntley, D. A. 2002 Self-organization mechanisms for the formation of nearshore crescentic and transverse sand bars. J. Fluid Mech. 465, 379-410.

Calvete, D. \& De Swart, H. E. 2003 A nonlinear model study on the long-term behavior of shore face-connected sand ridges. J. Geophys. Res. 108, doi:10.1029/2001JC001091.

Calvete, D., Falqués, A., De Swart, H. E. \& Walgreen, M. 2001 Modelling the formation of shoreface-connected sand ridges on storm-dominated inner shelves. J. Fluid Mech. 441, $169-193$.

Calvete, D., Dodd, N., Falqués, A. \& van Leeuwen, S. M. 2005 Morphological development of rip channel systems: normal and near normal wave incidence. J. Geophys. Res. 110, doi:10.1029/2004JC002803.

Castelle, B. 2004 Modélisation de l'hydrodynamique sédimentaire au-dessus des barres sableuses soumises à l'action de la houle: application à la côte aquitaine. $\mathrm{PhD}$ thesis, Université Bordeaux I, France.

Christensen, E., Deigaard, R. \& Fredsoe, J. 1994 Sea bed stability on a long straight coast. In Coastal Engineering 1994, vol. 4 (ed. B. L. Edge), pp. 1865-1879. ASCE, New York. 
Coco, G., Huntley, D. A. \& O'Hare, T. J. 2000 Investigation of a self-organization model for beach cusp formation and development. J. Geophys. Res. 105, 21991-22002.

Coco, G., Caballeria, M., Falqués, A. \& Huntley, D. H. 2002 Crescentic bars and nearshore selforganization processes. In Coastal Engineering 2002, vol. 3 (ed. J. M. Smith), pp. 3765-3777. World Scientific.

Damgaard, J., Dodd, N., Hall, L. \& Chesher, T. 2002 Morphodynamic modelling of rip channel growth. Coastal Engng 45, 199-221.

Deigahrd, R., Drønen, N., Fredsoe, J., Jensen, J. H. \& Jørgesen, M. P. 1999 A morphological stability analysis for a long straight barred coast. Coastal Engng 36, 171-195.

van Enckevort, I. M. J., Ruessink, B. G., Coco, G., Suzuki, K., Turner, I. L., Plant, N. G. \& Holman, R. A. 2004 Observations of nearshore crescentic sandbars. J. Geophys. Res. 109, doi:10.1029/2003JC002214.

Evans, O. F. 1938 The classification and origin of beach cusps. J. Geology 46, 615-627.

FACHIN, S. \& SANCHO, F. 2004 M-shorecirc: a new morphodynamical model. Presented at International Coastal Symposium - ICS 2004. J. Coastal Res. Special Issue 39 (to appear).

FALQuÉs, A. 1989 Formación de topografía rítmica en el Delta del Ebro. Revista de Geofísica 45, 143-156.

Falqués, A., Montoto, A. \& Iranzo, V. 1996 Bed-flow instability of the longshore current. Cont. Shelf Res. 16, 1927-1964.

Falqués, A., Coco, G. \& Huntley, D. A. 2000 A mechanism for the generation of wave-driven rhythmic patterns in the surf zone. J. Geophys. Res. 105, 24071-24 088.

Guilcher, A., Godard, A. \& Visseaux, E. 1952 Les cretes et sillons obliques de l'estran des Landes de Gascogne. Comite d'Oceanogr. et d'Etudes des Cotes Bull. 4, 151-157.

Hino, M. 1974 Theory on formation of rip-current and cuspidal coast. In Coastal Engineering 1974, pp. 901-919. ASCE, New York.

Horikawa, K. 1988 Nearshore Dynamics and Coastal Processes. University of Tokyo Press.

Hunter, R. E., Clifton, H. E. \& Phillips, R. L. 1979 Depositional processes, sedimentary structures, and predicted vertical sequences in barred nearshore systems, Southern Oregon coast. J. Sediment. Petrol. 49, 711-726.

IDIER, D. \& AstruC, D. 2003 Analytical and numerical modeling of sandbanks dynamics. J. Geophys. Res. 108, 3060, doi:10.1029/2001JC001205.

Klein, M. D., Schuttelaars, H. M. \& Stive, M. J. F. 2004 Influence of sediment transport formulation on the linear stability of planar and barred coasts. In Coastal Engineering 2004, vol. 3 (ed. J. M. Smith), pp. 2716-2728. World Scientific.

KnAaPen, M. 2001 Predicting large waves in erodible sand beds. PhD thesis, Universiteit Twente.

Komarova, N. L. \& Newell, A. C. 2000 Nonlinear dynamics of sand banks and sand waves. J. Fluid. Mech. 415, 285-321.

Konicki, K. M. \& Holman, R. A. 2000 The statistics and kinematics of transverse bars on an open coast. Mar. Geol. 169, 69-101.

Lafon, V., Dupuis, H., Howa, H. \& Froidefond, J. M. 2002 Determining ridge and runnel longshore migration rate using spot imagery. Oceanol. Acta 25, 149-158.

Longuet-Higgins, M. S. \& Stewart, R. W. 1964 Radiation stresses in water waves: a physical discussion with applications. Deep-Sea Res. 11, 529-562.

MeI, C. C. 1989 The Applied Dynamics of Ocean Surface Waves, Advanced Series on Ocean Engineering, vol. 1. World Scientific.

Nemeth, A. 2003 Modelling offshore sand waves. PhD thesis, Universiteit Twente.

Niederoda, A. W. \& Tanner, W. F. 1970 Preliminary study on transverse bars. Mar. Geol. 9, $41-62$.

Pedreros, R., Howa, H. L. \& Michel, D. 1996 Application of grain size trend analysis for the determination of sediment transport pathways in intertidal areas. Mar. Geol. 135, $35-49$.

Reniers, A. J. H. M., Roelvink, J. A. \& Thornton, E. B. 2004 Morphodynamic modeling of an embayed beach under wave group forcing. J. Geophys. Res. 109, doi:10.1029/2002JC001586.

RIBAS, F. 2004 On the growth of nearshore sand bars as instability processes of equilibrium beach states. PhD thesis, Appl. Physics Dept., Univ. Politècnica de Catalunya, Barcelona, Spain.

Ribas, F., Falqués, A. \& Montoto, A. 2003 Nearshore oblique sand bars. J. Geophys. Res. 108, 3119, doi:10.1029/2001JC000985. 
Roos, P. C., Hulsher, S. J. M., Knaapen, M. A. F. \& Damme, R. M. J. V. 2004 The crosssectional shape of tidal sandbanks: modeling and observations. J. Geophys. Res. 109, doi:10.1029/2003JF000070.

Schramkowski, G., Schuttelaars, H. M. \& DE Swart, H. E. 2004 Non-linear channel-shoal dynamics in long tidal embayments. Ocean Dyn. 54, 399-407.

SchuttelaARs, H. M. 1997 Evolution and stability analysis of bottom patterns in tidal embayments. PhD thesis, Universiteit Utrecht, Faculteit Wiskunde en Informatica, Utrecht, The Netherlands.

Short, A. D. 1994 Coastal photograph. J. Coastal Res. 10, 250.

Short, A. D. 1999 Handbook of Beach and Shoreface Morphodynamics. Wiley.

Sonu, C. J. 1968 Collective movement of sediment in littoral environment. In Coastal Engineering 1968, pp. 373-400. ASCE, New York.

Soulsby, R. L. 1997 Dynamics of Marine Sands. Thomas Telford, London.

Thornton, B. \& GuzA, R. T. 1983 Transformation of wave height distribution. J. Geophys. Res. 88, $5925-5938$.

Trowbridge, J. H. 1995 A mechanism for the formation and maintenance of shore-oblique sand ridges on storm-dominated shelves. J. Geophys. Res. 100, 16071-16086.

Werner, B. T. \& FinK, T. M. 1993 Beach cusps as self-organized patterns. Science 260, 968-971.

YU, J. \& SLinn, D. N. 2003 Effects of wave-current interaction on rip currents. J. Geophys. Res. 108, 3088, doi:10.1029/2001JC001105. 